\title{
Microwave Synthesis of Core-Shell Structured Biocompatible Magnetic Nanohybrids in Aqueous Medium
}

\author{
Ling $\mathrm{Hu}^{1}$, Aurélien Percheron 1 , \\ Denis Chaumont ${ }^{1}$ and Claire-Hélène Brachais ${ }^{2}$ \\ ${ }^{1}$ Laboratoire Interdisciplinaire Carnot de Bourgogne, Université de Bourgogne \\ ${ }^{2}$ Institut de Chimie Moléculaire de l'Université de Bourgogne, \\ Université de Bourgogne, \\ France
}

\section{Introduction}

In the past decade, biocompatible magnetic nanohybrids, i.e. materials consisting of an inorganic core encapsulated by a biocompatible polymeric corona, went throw various developments in biomedical applications especially in the fields of diagnosis and therapy. Numerous descriptions of their syntheses can be found in the literature (Zhang et al., 2002; Flesch et al., 2004; Fan et al., 2007; etc). These two-steps protocols often describe the use of organic or aqueous solvents, classical thermal heating, long time reaction as well as fastidious exchange and drying steps. In recent years, microwave heating has been proven to be a very original technology for nanoparticles synthesis due to its almost instantaneous "in core" heating of materials in a homogeneous and selective way. As a consequence, this technology allows an interesting control over crystallization rate and size of the nanomaterials (Bellon et al., 2001; Michel et al., 2001; etc). The formation of magnetic nanoparticles is usually realized in aqueous medium. However, the functionalization of magnetic nanoparticles is mainly conducted in organic solvent. For further biomedical applications, it seems favorable to realize these different grafting steps maintaining initial aqueous medium, thus avoiding the solvent exchanges and the particles drying. In this context, we can summarize the objective of this chapter as the study of new methods to obtain core-shell structured nanohybrids in aqueous medium from iron oxide nanoparticles and water-soluble biocompatible polymers. Is it possible to obtain iron oxide colloidal suspension and well-defined nanohybrids with simplified protocols and relatively short microwave heating time? This chapter is divided is three part, consisting for the first one, of a general presentation of biocompatible magnetic nanohybrids (properties, applications and synthesis). The second part deals with the principles of microwave heating and the description of microwave-assisted synthesis of inorganic nanoparticles. Finally, the last part is dedicated to the use of microwave heating towards magnetic nanohybrid synthesis compared to classical thermal heating process with a focus on nanoparticles characterization (morphology, size and grafted amount of polymer). 


\section{Biocompatible magnetic nanohybrids}

\subsection{Definition and properties}

Nanoscience is an interdisciplinary knowledge-generating domain which has the potential to create many advances in diagnosis and therapy. Nanomaterials such as magnetic nanoparticles and more especially iron oxide nanoparticles like magnetite $\mathrm{Fe}_{3} \mathrm{O}_{4}$ and maghemite $\gamma-\mathrm{Fe}_{2} \mathrm{O}_{3}$, present three very interesting properties for in vivo applications, which depend on their magnetic capacities. The most simple and natural property is their movement in a predetermined direction like a magnet when they are in a magnetic field (Gupta \& Curtis, 2004). These particles can also produce a strong signal during a scan using a magnetic field, in RMI analysis for example (Baghi et al., 2005; Schultz et al. 1999). The third property is their superparamagnetic behaviour, i.e. they have not persistent magnetic field when no magnetic field is applied. In this case, the temperature of the particles increases when they are subjected to a varying magnetic field with a suitable frequency (Flesch et al., 2005a). Furthermore, these nanoparticles can be easily recycled by human cells using the classic metabolic pathways of iron treatment (Mowat, 2007). They thus provide new properties compared to conventional drugs. Their applications will be more detailed in Part 2.2.

For their utilization in diagnosis and therapy, nanoparticles can be injected intravenously before being delivered by the blood circulation to the treated area. The nanoparticles can be also injected directly to the treated area. In the first case, after their injection in the blood circulation, the nanoparticles are quickly covered by plasma protein. This process is the first implementation of the immune system and makes the nanoparticles recognizable by macrophages (Davis, 1997). Nanoparticles capture and elimination by macrophages strongly limit their lifetime in the body and therefore their medical uses. An efficient way to overcome this problem is to make discrete nanoparticles by grafting a biocompatible polymer layer on their surfaces (Figure 1). The major difficulty is to find a polymer which is perfectly compatible with the human body and can be easily grafted onto an inorganic material. Biocompatibility is one of the most important characteristics of a biomedical polymer material which can provide a function with an appropriate response without any

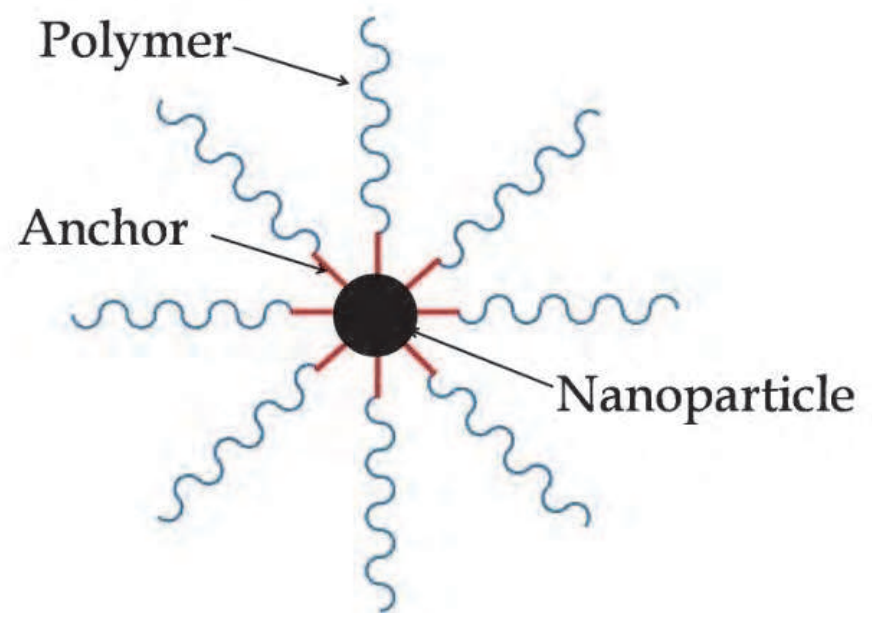

Fig. 1. Schematic representation of a core-shell nanohybrid 
adverse effects on the biological environment. The biocompatibility of polymers depends largely on their interactions with the tissues during their whole stay in the human body. The surface composition and the surface state of a biomaterial are two important factors to evaluate its biocompatibility. Usually, the polymers used to increase half life in the human body are hydrophilic polymers. Indeed, the grafting of hydrophilic polymer onto inorganic nanoparticles avoids the process of recovering and decreases their rate of elimination (Lu et al., 1999; Gaur et al., 2000). It is not the same case for the hydrophobic particle surfaces which are easily covered by blood plasma components and removed rapidly from the blood circulation (Gupta \& Curtis, 2004).

A second essential point of the utilization of magnetic nanoparticles for diagnosis end therapy is their suspension stability. In the case of nanohybrids, the stabilization is ensured by the repulsive forces between interacting polymers attached to the particle surfaces and prohibiting the inter-particle contact. The total potential energy curve of this particlepolymer system presents a potential barrier. When the polymer chains interpenetrate, there is a loss of configuration entropy which increases the free energy of the system and then the repulsive forces between the chains can take place. The physical barrier also helps to reduce the Van der Waals forces between particles by keeping them at a certain distance. The presence of polymer on the nanoparticle surfaces gives thus better dispersion stability. Table 1 gives some examples of polymers which can be used in biomedical applications.

\begin{tabular}{|c|c|c|}
\hline Polymer & Advantages & Reference \\
\hline PEG & $\begin{array}{r}\text { Improves the circulation time of nanoparticles in the blood and } \\
\text { the efficiency of internalization of nanoparticles } \\
\text { PVP }\end{array}$ & $\begin{array}{c}\text { Zhang et al., 2002; } \\
\text { Gupta \& Curtis, } \\
\text { 2004 }\end{array}$ \\
\hline PVA & $\begin{array}{r}\text { Stabilizes the colloidal solution and } \\
\text { improves the circulation time of nanoparticles in the blood. }\end{array}$ & D'Souza et al., 2004 \\
\hline PAA & Increases the stability and biocompatibility of nanoparticles & Changez et al., 2003 \\
\hline PCL & $\begin{array}{r}\text { Used as biomaterials for prostheses, } \\
\text { sutures and controlled release systems }\end{array}$ & Désévaux, 2002 \\
\hline PMMA & $\begin{array}{r}\text { Used for prosthetic constraint but not easily sterilizable } \\
\text { (by alcohol for example) }\end{array}$ & $\begin{array}{c}\text { Bonnans-Plaisance } \\
\text { et al., 2001 }\end{array}$ \\
\hline PVC & $\begin{array}{r}\text { Widely used in medicine but not in prosthesis, because of the } \\
\text { plasticizer, which diffuses into the blood }\end{array}$ & $\begin{array}{c}\text { Drakakis et al., } \\
\text { 2008 }\end{array}$ \\
\hline PTFE & $\begin{array}{r}\text { Very hydrophobic, flexible, non-reactive } \\
\text { Adapted to prostheses of blood vessels / arteries }\end{array}$ & Chen et al., 2003 \\
\hline Dextran & $\begin{array}{r}\text { Stabilizes the colloidal solution and improves the circulation } \\
\text { time of nanoparticles in the blood }\end{array}$ & Berry et al., 2003 \\
\hline Chitosan & Used as a no viral vector for gene therapy & Khor \& Lim, 2003 \\
\hline
\end{tabular}

Table 1. Some examples of biocompatible polymers used in medical application. (PEG: poly(ethyleneglycol); PVP: poly(vinylpyrrolidone); PVA: poly(vinylalcohol); PAA: poly(acrylicacid); PCL: poly(E-caprolactone); PMMA: poly(methylmethacrylate); PVC: poly(vinylchloride); PET: poly(ethyleneterephtalate); PTFE: poly(tetrafluorethylene)) 


\subsection{Potential therapeutic applications}

Different applications of nanohybrids in the medical world depend directly on their properties regarding to Part 2.1 (controlled movement in a magnetic field; temperature rise in an alternating magnetic field; strong magnetic response in medical image analysis). Their principal applications can be resumed in three classes and are described below:

- contrast agent for Magnetic Resonance Imaging (MRI);

- mediators of magnetic hyperthermia treatment;

- $\quad$ nanovectors for drug delivery by magnetic targeting.

\section{Contrast enhancement of Magnetic Resonance Images}

Magnetic Resonance Imaging (MRI) is a non-invasive imaging technique widely used in clinical for determining the functional parameters associated or not with pathologies. The use of contrast agents is necessary to target specifically certain biological mechanisms. It is well known that the introduction of magnetic nanoparticles in tissues allows obtaining a strong signal from MRI scanner. Magnetic nanoparticles offer many advantages (high specific magnetic moment, biocompatibility, functionalizable surface etc.) compared with the classical gadolinium contrast agents (Kubaska et al., 2001).

A wide variety of nanohybrids was already studied, differing in particle size or type of cover material. Particle size influences their physico-chemical and pharmacokinetic properties (Brigger et al., 2002). Lee et al. presented the synthesis and characterization of nanoparticles of maghemite $\gamma-\mathrm{Fe}_{2} \mathrm{O}_{3}$ coated with poly(vinylpyrrolidone) (PVP) (Lee et al., 2006). MTT cytotoxicity test, which is a rapid counting method of living cells, revealed the excellent biocompatibility of grafted nanoparticles. Observation of MRI images of distribution of grafted nanoparticles into the rabbit marginal vein showed a darker color of the liver after particles injection. Thus, the significant improvement in the detection of liver lesions by MRI using magnetic nanohybrids as contrast agent is proved.

\section{Targeted cancer cell destruction with magnetic hyperthermia}

The magnetic hyperthermia, a well-known therapy for cancer treatment, exposes the human cancer tissues to an alternating magnetic field which can not be absorbed by living tissues although can be applied within the whole human body. When magnetic particles are subjected to an alternating magnetic field, heat energy is produced due to the magnetic hysteresis loss. The amount of heat energy produced depends on the nature of magnetic materials and the properties of magnetic field. This magnetic therapy is based on the fact that cancer cells can be destroyed at a temperature around $43^{\circ} \mathrm{C}$ (Berry et al. 2003), whereas normal cells can survive at higher temperatures.

Some experiments were performed on animals or cancer cells in order to detect the therapeutic effects of magnetic nanohybrids on different types of tumours. Wada et al. have proven the effectiveness of magnetic nanohybrids (magnetite $\mathrm{Fe}_{3} \mathrm{O}_{4}$-dextran) (MD) for hyperthermia against cancer of the mouth (Wada et al., 2003). A suspension of MD was injected into tumours of the tongue and the tongue was heated to $43-45{ }^{\circ} \mathrm{C}$ by applying a magnetic field of $500 \mathrm{kHz}$. Owing to this technique, the inhibition of tumour growth is more effective than that of untreated tumours.

\section{Magnetic targeting for site-specific drug delivery}

Magnetic targeting drug delivery is an interesting technique for administration of pharmacologically active molecules. The objective is to improve their therapeutic index. The term vector refers to the molecular structure or the colloidal compounds used to carry or 
transport molecule of biological interest into cells. The role of the vector is both to protect the active molecules against the chemical or enzymatic degradation occurring in vivo and also to transport them to their sites of action.

Plassat et al. (2008) showed that the liposomes, sterically stabilized by hydrophilic chains of polyethylene glycol and encapsulating superparamagnetic maghemite $\gamma-\mathrm{Fe}_{2} \mathrm{O}_{3}$ nanocrystals, can be exploited to target breast cancer tumours. This exploitation is possible by applying an external magnetic field gradient at the region of interest, and by associating the nanohybrids to an antiestrogen (RU 58668), which is effective to stop the growth of estrogen-dependent tumours (Maillard et al., 2006).

\subsection{Synthesis of biocompatible magnetic nanohybrids 2.3.1 Preparation methods in the literature}

The use of an anchor is necessary to attach the organic component (the polymer) to the inorganic component (the nanoparticle) (Figure 1). The role of this anchor is to create a strong bond such as an ionic or a covalent bond between the two components to avoid desorption (Jo \& Park, 2000). Macromolecules ionically attached to the particles surface are very sensitive to the dissolution and / or the depletion. The conditions of utilization of this type of nanohybrids would be rather limited for medical applications, since the biological environment could separate the polymer from the nanoparticle (Delair et al., 2003). In addition, the anchor also acts as a spacer between nanoparticle core and polymer chains to facilitate the approach of the reactive polymer to the nanoparticle.

The core-shell structured nanohybrid materials can be prepared following two approaches: grafting from and grafting to, considering the polymers already formed or not (Figure 2). Table 2 shows various examples of the synthesis of nanohybrids using these two methods.

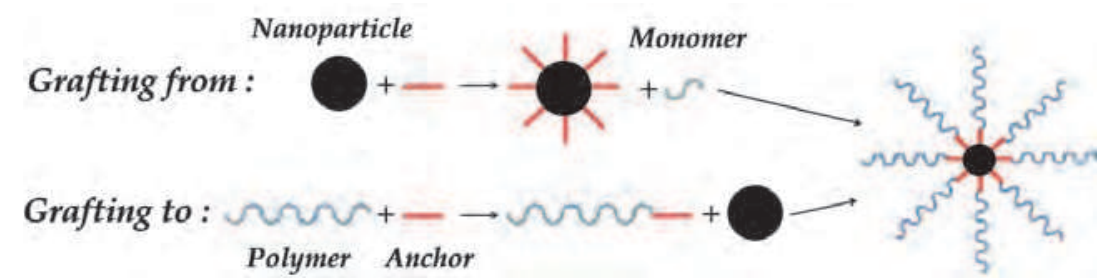

Fig. 2. Presentation of two principal grafting methods: grafting from and grafting to

\section{Grafting from}

Grafting from includes monomer adsorption onto particles followed by a subsequent polymerization which can be catalyzed by an initiator promoting the process (Ninjbadgar et al., 2004). This approach proceeds in two steps: the anchoring on the particle surface and the polymerization of monomer from the anchor.

\section{Grafting to}

In the Grafting to process, the polymer is modified to react with reactive groups of the nanoparticles surface (Brachais et al. 2010; $\mathrm{Hu}$ et al. 2008). In this case, the grafting is preformed either by placing an anchoring system on the particle surface or by a prior functionalization of polymer. The length of grafted chains on the nanoparticles is determined by the choice of the starting polymer. 


\begin{tabular}{|c|c|c|c|c|c|c|c|}
\hline Protocol & Core & Shell & Solvent & Anchor & $\begin{array}{l}\text { Synthesis } \\
\text { parameters }\end{array}$ & $\begin{array}{l}\text { Grafted } \\
\text { amount a }\end{array}$ & Reference \\
\hline \multirow{7}{*}{$\begin{array}{l}\text { Grafting } \\
\text { from }\end{array}$} & $\mathrm{\gamma}-\mathrm{Fe}_{2} \mathrm{O}_{3}$ & PCL & toluene & AAPM & $\begin{array}{c}50^{\circ} \mathrm{C} \text {, under } \mathrm{N}_{2} \\
48 \mathrm{~h}\end{array}$ & $10 \%$ & $\begin{array}{c}\text { Flesch et al., } \\
2005 \mathrm{~b}\end{array}$ \\
\hline & $\gamma-\mathrm{Fe}_{2} \mathrm{O}_{3}$ & PMMA & DMF & CDS & $\begin{array}{c}70^{\circ} \mathrm{C}, 10 \mathrm{~h}, \\
\text { under } \mathrm{N}_{2}\end{array}$ & - & $\begin{array}{r}\text { Ninjbadgar } \\
\text { et al., } 2004 \\
\end{array}$ \\
\hline & $\gamma-\mathrm{Fe}_{2} \mathrm{O}_{3}$ & PEG & water & MPS & $\begin{array}{c}70^{\circ} \mathrm{C} \text {, under } \mathrm{N}_{2} \\
23 \mathrm{~h}\end{array}$ & $20 \%$ & $\begin{array}{c}\text { Flesch et al., } \\
2005 c\end{array}$ \\
\hline & $\mathrm{Fe}_{3} \mathrm{O}_{4}$ & PDMAEMA & DMF & BIB & $\begin{array}{c}90^{\circ} \mathrm{C}, 24 \mathrm{~h}, \\
\text { under } \mathrm{Ar}\end{array}$ & $14 \%$ & $\begin{array}{c}\text { Zhou et al., } \\
2009\end{array}$ \\
\hline & $\mathrm{Fe}_{3} \mathrm{O}_{4}$ & SPAN & $\begin{array}{c}\mathrm{HCl} 0,2 \mathrm{M} \\
\text { aqueous } \\
\text { solution }\end{array}$ & APTMS & $26 \mathrm{~h}$, under $\mathrm{N}_{2}$ & $12 \%$ & $\begin{array}{c}\text { Reddy et al., } \\
2007\end{array}$ \\
\hline & $\mathrm{Fe}_{3} \mathrm{O}_{4}$ & P(PEGA) & THF & CPA & $30^{\circ} \mathrm{C}, 18 \mathrm{~h}$ & $34 \%$ & $\begin{array}{c}\text { Fan et al., } \\
2007 \\
\end{array}$ \\
\hline & $\mathrm{NiFe}_{2} \mathrm{O}_{4}$ & PMAA & water & SDS & $\begin{array}{c}70^{\circ} \mathrm{C}, \text { under } \mathrm{Ar}, \\
2 \mathrm{~h}\end{array}$ & - & \begin{tabular}{|c|} 
Rana et al., \\
2007 \\
\end{tabular} \\
\hline \multirow{7}{*}{$\begin{array}{c}\text { Grafting } \\
\text { to }\end{array}$} & $\gamma-\mathrm{Fe}_{2} \mathrm{O}_{3}$ & dextran & water & APS & $28 \mathrm{~h}$, under $\mathrm{N}_{2}$ & - & $\begin{array}{c}\text { Mornet et al. } \\
2005 \\
\end{array}$ \\
\hline & $\gamma-\mathrm{Fe}_{2} \mathrm{O}_{3}$ & PCL & DMF & IPTS & $\begin{array}{c}120^{\circ} \mathrm{C} \text {, under } \mathrm{N}_{2}, \\
22 \mathrm{~h}\end{array}$ & $15 \%$ & $\begin{array}{c}\text { Flesch et al., } \\
2004\end{array}$ \\
\hline & $\gamma-\mathrm{Fe}_{2} \mathrm{O}_{3}$ & PVI & $\begin{array}{l}\text { toluene/ } \\
\text { methanol }\end{array}$ & MPS & $48 \mathrm{~h}$, under $\mathrm{N}_{2}$ & - & $\begin{array}{c}\text { Takafuji et } \\
\text { al., } 2004\end{array}$ \\
\hline & $\gamma-\mathrm{Fe}_{2} \mathrm{O}_{3}$ & PANI & toluene & $\begin{array}{l}\text { Oleic } \\
\text { acid }\end{array}$ & $24 \mathrm{~h}$, under $\mathrm{N}_{2}$ & $6 \%$ & $\begin{array}{c}\text { Dallas et al., } \\
2006\end{array}$ \\
\hline & $\mathrm{Fe}_{3} \mathrm{O}_{4}$ & $m$ PEG-PCL & water & $\begin{array}{l}\text { Oleic } \\
\text { acid }\end{array}$ & $\begin{array}{c}\text { Troom, } 24 \mathrm{~h} \text {, under } \\
\mathrm{N}_{2}\end{array}$ & $12 \%$ & $\begin{array}{c}\text { Meerod et al. } \\
2008\end{array}$ \\
\hline & $\mathrm{Fe}_{3} \mathrm{O}_{4}$ & PEG & water & APS & $\begin{array}{c}60^{\circ} \mathrm{C}, 4 \mathrm{~h} \text {, under } \\
\mathrm{N}_{2}\end{array}$ & - & $\begin{array}{c}\text { Zhang et al. } \\
2002\end{array}$ \\
\hline & $\mathrm{NiFe}_{2} \mathrm{O}_{4}$ & PVA & water & - & $\begin{array}{c}25^{\circ} \mathrm{C}, 15 \mathrm{~h}, \\
\text { under } \mathrm{N}_{2} \\
\end{array}$ & - & $\begin{array}{c}\text { Sindhu et al. } \\
2006\end{array}$ \\
\hline
\end{tabular}

a determined by thermogravimetric analysis

Table 2. Synthesis of nanohybrids using "grafting from" and "grafting to" methods.

(PCL: poly(e-caprolactone); AAPM: N-(2-aminoethyl)-3-aminopropyltrimethoxysilane;

PMMA: poly(methylmethacrylate); DMF: N'N-dimethylformamide;

CDS: (chloromethyl)phenylethyl-dimethylchlorosilane; PEG: polyethylene glycol;

MPS: methacryloxypropyltrimethoxysilane;

PDMAEMA: poly(2-(dimethylamino)ethylmethacrylate);

BIB: N-bromoisobutyrate acid; SPAN: poly(aniline-co-aminobenzenesulfonic acid);

APTMS: aminopropyltrimethoxysilane;

P(PEGMA): poly(poly(ethyleneglycol) monomethacrylate); THF: tetrahydrofurane;

CPA: chloropropionic acid; PMAA: poly(methacrylicacid); SDS: sodium dodecylsulfate;

APS: 3-aminopropyltrimethoxysilane; IPTS: 3-isocyanatopropyltriethoxysilane;

PVI: poly(1-vinylimidazole); PANI: poly(aniline); PVA: poly(vinyl alcohol)) 


\section{Comparison between grafting from and grafting to}

The literature shows that grafting from process allows reaching higher contents of grafted polymers whereas grafting to process allows a good control over the length of the polymeric chains. Furthermore, grafting to method can be applied to all types of polymers possessing reactive ends. The length of polymer chain is known and well controlled. The only parameter to control is the grafting rate. Thus nanocomposites obtained by this method can be better characterized.

\subsubsection{Reaction mechanisms proposed in the literature}

In this part, we present the various steps proposed in the literature concerning the grafting reaction mechanism of polyethylene glycol (PEG) onto an inorganic core (iron oxide nanoparticle) using 3-isocyanatopropyltriethoxysilane (IPTS) as the anchor. PEG has been used widely for surface modification because of its unique properties such as hydrophilicity, flexibility, nontoxicity and nonimmunogenecity (Jo \& Park, 2000).

\section{Formation of a urethane bond}

In the case of anchoring of polymer chains, Kim et al. (2005) studied the functionalization of polyethylene glycol (PEG) with 3-isocyanatopropyltriethoxysilane (IPTS) (Figure 3), using dibutyl tin dilaurate (DBTL) as catalyst in tetrahydrofuran (THF).
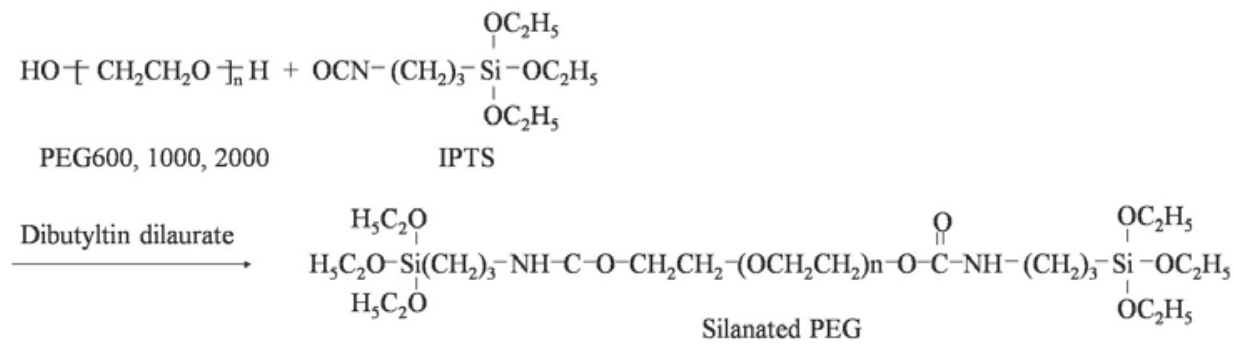

Fig. 3. Functionalization of PEG by IPTS in THF (Kim et al., 2005)

Initially, the isocyanate group (NCO) of IPTS reacts with the hydroxyl end of the polymer. It is mainly the $\mathrm{N}=\mathrm{C}$ bond which is involved in most reactions of isocyanates, for example the reaction between an alcohol and an isocyanate function (Figure 3). The resulting urethane bond, formed after the condensation, is generally thermally stable (Barruet, 2007).

However, isocyanates react very easily with water and undergo a rapid hydrolysisdecarboxylation reaction (Figure 4). The amine formed after the hydrolysis is able to react with another isocyanate function to produce urea, which has very high thermal stability preventing possible subsequent substitution (Figure 5) (Barruet, 2007). Thus it is important to avoid the presence of humidity in the reaction medium during the grafting step using isocyanate functions.

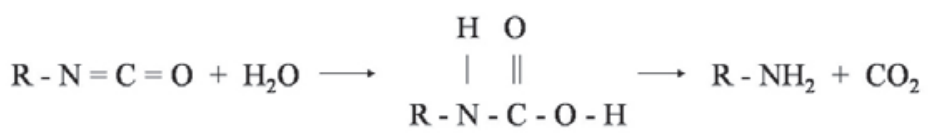

Fig. 4. Decarboxylation of isocyanates in water (Barruet, 2007) 


$$
\mathrm{R}-\mathrm{NH}_{2}+\mathrm{R}^{\prime}-\mathrm{N}=\mathrm{C}=\mathrm{O} \longrightarrow \quad \begin{array}{ccc}
\mathrm{H} & \mathrm{O} & \mathrm{H} \\
\mathrm{R}^{\prime}-\mathrm{N} & \| & \mid \\
\mathrm{C}-\mathrm{N}-\mathrm{R}
\end{array}
$$

Fig. 5. Formation of urea after the reaction between an amine and an isocyanate (Barruet, 2007)

\section{Grafting of alkoxysilane on the nanoparticles}

Alkoxysilane functions introduced during the anchoring are then used for the grafting on the nanoparticles. According to Zhang et al. (2002), the grafting of PEG on the magnetite nanoparticles takes place by direct reaction between surface hydroxyl groups $(-\mathrm{OH})$ of magnetite nanoparticles and anchor siloxane functions of polymer. PEG is grafted on the surface of magnetite by forming a covalent Fe-O-Si bond (Figure 6).

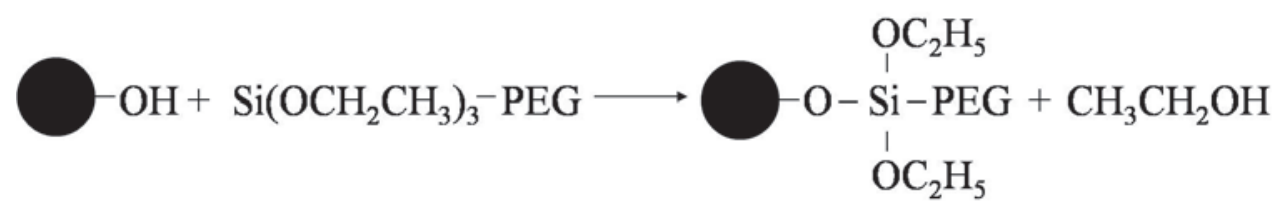

Fig. 6. Grafting reaction of functionalized PEG with magnetite nanoparticle (Zhang et al., 2002)

\section{Different catalytic media for the grafting process of alkoxysilanes}

It is possible to perform the grafting process under acidic, basic catalytic media or with organometallic catalyst, for catalyzing the initiation of condensation between the hydroxyl groups of particles and the silanol groups.

\section{Acid catalysis}

Alkoxysilane hydrolysis in acidic medium is based on an electrophilic substitution mechanism leading to the formation of silanol (Grignon-Dubois et al., 1980). The following condensation between silanol and surface hydroxyl functions of the nanoparticles lays essentially on an equilibrium between the protons and the silanol functions forming the temporary charged species (Figure 7). These positively charged species strongly attract the surface hydroxyl groups of nanoparticles.

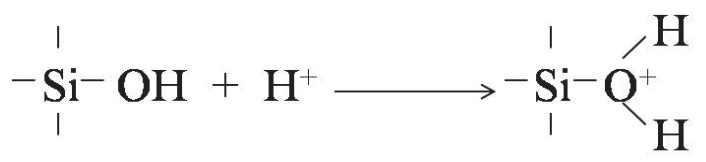

Fig. 7. Temporary formation of positively charged species in acidic medium

\section{Basic catalysis}

The basic hydrolysis is based on a nucleophilic substitution mechanism (Buurma et al., 2003). An ionic equilibrium is established between the silanols and the hydroxyde ions, leading to the formation of silanolate anions (Figure 8). 


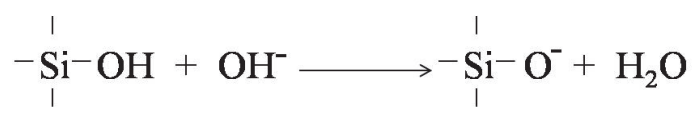

Fig. 8. Formation of silanolate anions in basic medium

\section{Organometallic catalysis}

Tin salts such as dibutyltin dilaurate (DBTL) are widely used as catalysts for reaction between the isocyanate and alcohol functions. The reaction mechanisms were well defined by Houghton \& Mulvaney (1996) and Brosse et al. (1995). Moreover, it was reported that the effect of DBTL is also to reduce the activation energy involved in the hydrolysis step of alkoxysilanes and to catalyze the condensation between silanol and hydroxyl functions (Kelnar \& Schätz, 1993; Narkis et al., 1985).

\subsection{Conclusion}

Nanohybrid particles combine the advantages of their two components: magnetic core (magnetic hyperthermia, strong signal in magnetic field and magnetic vectorization) and polymer corona (biocompatibility). These combinations are essential for medical uses. The preparation of magnetic nanoparticles is generally carried out in aqueous medium whereas the functionalization of the polymer is commonly performed in organic medium. However, the colloidal suspensions formed are widely used for medical diagnosis and pharmaceutical applications in aqueous phase. For those applications, a particle drying followed by a solvent exchange are necessary before the grafting of the polymer. It is important to note that the agglomeration of nanoparticles is easily formed during the drying process. This problem has already been described by several authors (Reddy et al., 2007; Ramirez \& Landfester, 2003; Sreeja \& Joy, 2007). In this case, the grafting of polymers is performed on particle clusters instead of nanoparticles. Therefore it seems advantageous to carry out the synthesis by avoiding the solvent exchanges. Furthermore the preparation time is quite long (until several hours) because of the separate steps as shown in Table 2. Thus the finding of an appropriate protocol for the synthesis of nanohybrids remains still important and necessary.

\section{Microwave synthesis}

\subsection{Principles of microwave heating}

The microwave region of the electromagnetic spectrum lies between infrared and radio frequencies. Their frequency ranges from $30 \mathrm{GHz}$ to $300 \mathrm{GHz}$ and the wavelengh from $1 \mathrm{~cm}$ to $1 \mathrm{~m}$. Equation 1 shows the relation between the energy $\mathrm{E}$, the frequency $v$ or the wavelength $\lambda$ of the radiation:

$$
E=h \cdot v=\frac{h \cdot c}{\lambda}
$$

where $\mathrm{h}$ is the Planck constant and $\mathrm{c}$ is the speed of light. The microwave photon energy is around $10^{-5} \mathrm{eV}$. This value is lower than the mean kinetic energy of Brownian motion $(0.017$ $\mathrm{eV})$, the hydrogen bonds (0.04 to $0.44 \mathrm{eV}$ ) and the covalent bonds (5 eV) (Michel, 2003a). Consequently, microwave field cannot be the origin of bond breaking.

The physical origin of microwave heating comes from the ability of some materials to convert electromagnetic energy into heat energy. Indeed, the electric component of 
microwave field can induces a polarization of the charge carriers of the material. In the case of materials with dielectric losses, the polarization inversion process is slower than the electric field inversion of the applied electric field. There is therefore the apparition of a phase shift between the both. This phase shift gives rise to the energy conversion. A part of electromagnetic energy is stored in the material and the other part is converted into heat energy. It is possible to quantify this part of energy by the dielectric permittivity $\tilde{\varepsilon}$ (a physical complex data) defined by Equation 2.

$$
\tilde{\varepsilon}=\varepsilon^{\prime}-\mathrm{j} \varepsilon^{\prime \prime}=\varepsilon_{0} \varepsilon_{\mathrm{r}}^{\prime}-\mathrm{j} \varepsilon_{0} \varepsilon_{\mathrm{r}}^{\prime \prime}
$$

where $\varepsilon_{0}$ is the dielectric permittivity in vacuum, $\varepsilon^{\prime}$ is the real part of dielectric permittivity, $\varepsilon^{\prime \prime}$ is the imaginary part of dielectric permittivity, $\varepsilon_{\mathrm{r}}^{\prime}$ is the real part of relative dielectric permittivity, and $\varepsilon_{\mathrm{r}}^{\prime \prime}$ is the imaginary part of relative dielectric permittivity. The real part corresponds to the electromagnetic energy stored and the imaginary part corresponds to the heating conversion. Then, the power dissipation $\mathrm{P}_{\text {diss }}$ within the material is proportional to $\varepsilon^{\prime \prime}$, according to Equation 3.

$$
P_{\text {diss }}=\iiint_{\text {material }} \omega \varepsilon^{\prime \prime}|E|^{2} d V
$$

where $\omega$ is the electric field pulsation and $\mathrm{E}$ is the electric field amplitude. It is interesting to note that the dielectric loss changes with temperature. Two cases may arise: a) the temperature dependence of dielectric loss is positive, and in that case there is an accelerating heating, which can lead to thermal runaway; b) this dependence is negative and the microwave heating is then self-regulated.

In conclusion, the material heating under microwave irradiation is dependent on three parameters: the material dielectric loss, the frequency and the amplitude of electric field. The dielectric parameter limits the material class that could be used, the frequency is fixed by the microwave device (usually $2,45 \mathrm{GHz}$ ), the intensity (square of the amplitude) or the power delivered is chosen by the user.

\subsection{Characteristics of microwave heating}

One of the most important features of microwave heating is the material volumetric heating (core heating), contrary to the classical heater devices working by convection and conduction. This property is the direct consequence of phase shift between electric field and dipolar moment of charge carriers. Thus the entire material volume is heated at the same time, contrary to the case of classical heating producing a spatial distribution of heat. Furthermore, the microwave heating kinetic could be very fast, several degrees by second. If the power applied is strong, about kilowatts over several tens of milliliters, the volumetric heating induces very high temperature within the material.

Pinto-Gateau (1995) showed the influence of the position and the distribution of electric field on the temperature evolution of the material heated. She showed also the importance of a rigorous control of the dimension and the position of the material in the microwave applicator. The simulations and experiments of microwave heating in the case of waterfilled tubes indicated that:

- Temperature increases more quickly when the electric field is orthogonal to the main material axe. 
- When water volume and power puissance are constant, heating kinetic depends on the tube diameter.

Consequently, a microwave heating system must allow to position as precisely as possible the material regarding to the electric field, and ensure the repeatability of experiments.

\subsection{Microwave heating devices}

\subsubsection{Generalities about microwave heating systems}

Figure 9 shows the main elements of a classical microwave heating system: the generator, the insulator, the waveguide (or coupler) and the applicator containing the reactor and the chemical precursors.

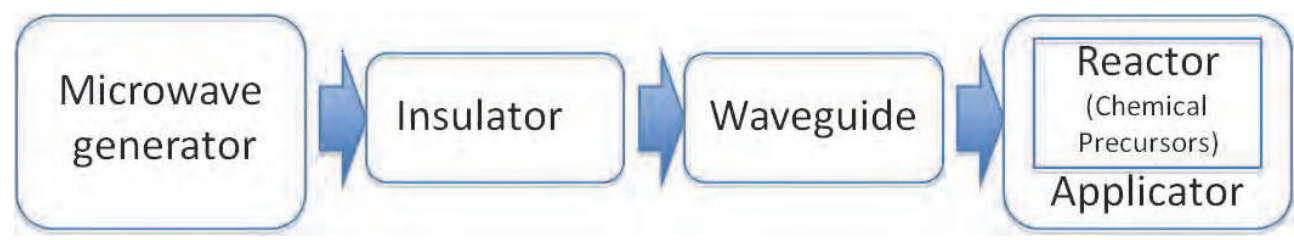

Fig. 9. Presentation of main elements of a classical microwave heating device

The microwave generator produces the microwave energy from the alternative electric network. It is composed of a magnetron. The most common commercial devices produce waves at $2.45 \mathrm{GHz}$ and power of about 1 or $2 \mathrm{~kW}$. The isolator protects the generator from any potentially destructive wave returns to the magnetron. It has a ferrite circulator which deflects the reflected fields on an absorbent filler, usually a water load. The transfer of energy between the generator and the applicator is provided by the waveguide (or coupler).

The applicator must transfer the energy under the best possible conditions to the material to be heated. Several types of applicator are available and depend on the desired applications. Progressive wave applicators are made of rectangular waveguides, split at the maximum electric field position and where the material to be heated circulates. The resonant applicators (or the resonant cavities) allow the optimum transfer of energy to the sample because of the containment of the microwave field. The condition of resonance is that the cavity dimensions are equal to an integer number of half-wavelengths. These cavities are qualified "single mode" or "multi mode" depending on their spatial distribution modes of energy. Some cavities, equipped with a piston, are tunable: the action on the piston causes a change in the length of the cavity and thus of the resonant frequency.

This microwave heating devices, we used, are specially designed by our research team in University of Burgundy

\subsubsection{The laboratory microwave refluxing (open reactor system)}

The laboratory microwave refluxing device we used, is composed by:

- A generator MSE (Microwave System Energy), output frequency: $2.45 \mathrm{GHz}$; continuous and adjustable output power from 0 to $2 \mathrm{~kW}$.

- An insulator (for generator protection).

- A waveguide to transfer of microwave energy between the generator and the refluxing reactor. The waveguide is equipped with a piston: the action on the piston causes a change in the length of the cavity and thus of the resonant frequency. 
- The quartz tube of the refluxing reactor is placed on the hole in the middle of the waveguide. The quartz tube containing the chemical precursors is topped with a classical reflux condenser for chemistry.

The advantages of a microwave refluxing heating device are numerous:

- Because of the core heating, there are no conduction or convection phenomena. The entire system volume is heated at the same time.

- The microwave heating is selective: its effectiveness depends on the dielectric losses of the reagents.

- The absence of thermal inertia of microwave reactor, owing to internal sources, allows the optimal temperature control.

- $\quad$ The energy is focused on the reactor and then provides a high power density and high temperature rise.

\subsubsection{The laboratory microwave autoclave reactor (closed reactor system)}

The laboratory microwave autoclave reactor we used, is composed by:

- A generator MSE (Microwave System Energy), output frequency: $2.45 \mathrm{GHz}$; continuous and adjustable output power from 0 to $2 \mathrm{~kW}$.

- An insulator (for generator protection) and a waveguide to transfer of microwave energy between the generator and the rectangular resonant cavity. The waveguide with radiating slots has a tuning plunger.

- A rectangular resonant cavity which contains the autoclave reactor placed in its middle.

- The autoclave is connected to pressure monitoring system. It is also possible to have an in situ temperature measurement using optic thermometry. In addition, the inert gas such as argon can be introduced into the reactor to work under inert atmosphere and to control the risk of explosion with flammable solvents, oxygen and possible electric sparks. The autoclave reactor body is composed of a polymer material, the polyetherimide (PEI). This material was chosen because of its transparency to microwaves which allows the full transfer of microwave energy to the reaction medium. The second reason is its usability under severe operating conditions of temperature and pressure induced by the microwave field. The PEI presents a good mechanical strength at high temperature. Finally, the material chosen must withstand to chemical species involved during synthesis. Inside the reactor, a container in Teflon ${ }^{\circledR}$ which is transparent to microwaves and chemically inert, contains the reaction medium. The Teflon ${ }^{\circledR}$ container can hold up to $20 \mathrm{~mL}$ of precursor solution.

The laboratory microwave autoclave reactor combines the advantages of a classical microwave heating device (see above) and the advantage of an autoclave reactor: the synthesis under pressure and at high temperatures $\left(12\right.$ bars, $\left.180{ }^{\circ} \mathrm{C}\right)$. Then, the laboratory microwave autoclave reactor allows a very fast temperature rise (around $5{ }^{\circ} \mathrm{C} . \mathrm{s}^{-1}$ ). This advantage gives very interesting perspectives due to the kinetic which is in the same order of magnitude than the reaction time. Stuerga \& Gaillard (1996) showed that the control of thermal paths allows the selective syntheses, and the heating rate can promote one reaction path among all the concurrent processes. The real-time control of pressure inside the reactor allows to adjust the generator power during synthesis to maintain the pressure at a setpoint (Bellon, 2000).

The advantages of the utilization of microwave heating in a closed reactor device (laboratory microwave autoclave reactor) are numerous. However, the use of certain 
compounds (such as glycols, ethers and alkanes) in a closed reactor could damage the system. In this case, the laboratory microwave refluxing device is used instead of the autoclave system. This open system provides the possibility to work safely in solution.

\subsection{Microwave-assisted synthesis}

We have seen the usefulness of microwave heating in comparison with other heating methods. During the synthesis in solution, this gives to particles synthesized under microwave field, some remarkable properties.

\subsubsection{Solvent effects on microwave synthesis}

\section{Aqueous medium}

Water is a solvent with high dipolar moment (1.84 Debye) and a strong dielectric constant $\left(\varepsilon_{\mathrm{r}}^{\prime}=78.5\right)$. Furthermore water has strong dielectric loses at $2.45 \mathrm{GHz}\left(\varepsilon_{\mathrm{r}}^{\prime \prime}=11\right.$ at $\left.20^{\circ} \mathrm{C}\right)$. These properties are sufficient to ensure a good conversion of electromagnetic energy into heat energy.

The synthesis in aqueous solution could be classified into two categories: the synthesis of nanoparticles by thermal initiation and the synthesis by basic initiation:

- Thermal initiation: In this case, the increase of temperature initiates the condensation process and thus the nanoparticle formation. The initiation step, more specially the nucleation step, is controlled by the heating kinetic. Microwave heating allows to separate the nucleation and growth steps. It must be noted that if microwave heating system is associated to an autoclave, the reaction temperature is higher than that in atmospheric pressure.

- Basic initiation: In the second case, in a basic medium, the initiation starts by forming a precipitate when the solutions are mixed. These precipitates are then placed in a microwave field. In this case, microwave heating controls the growth and the evolution of the precipitate instead of the initiation process (Daichuan et al., 1995).

\section{Organic solvents}

Simple alcohols are widely used in microwave synthesis. They are more employed than polyols due to their low toxicity. The alcoholic synthesis avoids the oxidation contrary to the aqueous solvent (Thanh et al., 2000; Cirera et al., 2000). The alcohol/water mixture presents a lower dielectric constant, and thus decreases the solubility of salts and starts the precipitation earlier (Choi \& Kim, 1999).

Glycols, especially ethylene glycol, are used for the synthesis of metal nanoparticles by the reduction of a hydroxide, a sulfate or a nitrate species. This process, called "polyol process" in the literature, is based on redox reactions and leads to finely divided metal powders (Komarneni et al., 2002; Harpeness \& Gedanken, 2005; Grisaru et al., 2003). Under conventional heating, this process is very long (several hours) and their transposition under microwave heating can divide the reaction time by 10 .

\subsubsection{Synthesis of nanoparticles by microwave heating}

Recent works of our laboratory showed that the singular and original microwave heating induces some interesting properties to the particles obtained by microwave heating (Bellon et al., 2001; Michel et al., 2001, 2003b; Combemale et al., 2005; Bousquet-Berthelin et al., 2008). 
The effects of the core heating, of the high power focused, of the non-diffusional heating process, of the fast temperature rise, are:

- quick synthesis

- $\quad$ high crystallinity of the oxides

- composition of polycation oxide is controlled

- crystalline phase is controlled

- $\quad$ size and size distribution controlled

- morphology controlled

- chemical selectivity

We proved the possibility to realize magnetic nanoparticles by microwave heating (Caillot et al., 2002; Caillot et al. 2004; Michel, 2003b). Microwave heating allows to accelerate chemical reactions, differents from the classical ones. Main advantage is its almost instantaneous "in core" heating of materials in a homogeneous and selective manner which results in a reduction of the processing time and energy cost.

Sreeja \& Joy (2007) synthesized maghemite nanoparticle of $10 \mathrm{~nm}$ from solution of $\mathrm{FeSO}_{4}$ and $\mathrm{FelCl}_{3}$ with MARS5 CEM system (max power of 1200W) in 25 min. Kulikov et al. (2003) prepared maghemite nanoparticles of $5 \mathrm{~nm}$ by microwave heating of $\mathrm{Fe}\left(\mathrm{NO}_{3}\right)_{3}$ in aqueous solution. The system was domestical microwave $(2450 \mathrm{MHz}, 850 \mathrm{~W})$. These examples show that microwave heating allows to decrease the reaction time compared to classical heating (Ge et al., 2006).

\section{Contribution of microwave heating towards the magnetic nanohybrids synthesis}

As previously stated in paragraph 2.3, magnetic nanohybrids are commonly synthesized in two steps under classical heating. The first step is the preparation of magnetic nanoparticles, and the second step is the grafting of polymers onto the nanoparticles. The major problems imposed by these protocols are the obligation of a solvent exchange and the long reaction times (Table 2).

We developed a new approach of the magnetic nanohybride aqueous synthesis: a microwave-assisted one-step grafting of the polymer on the maghemite nanoparticles during their formation. mPEG was used because it has only one alcohol end function which does not allow the intraparticle grafting or the interparticle grafting (Werne \& Patten, 2001).

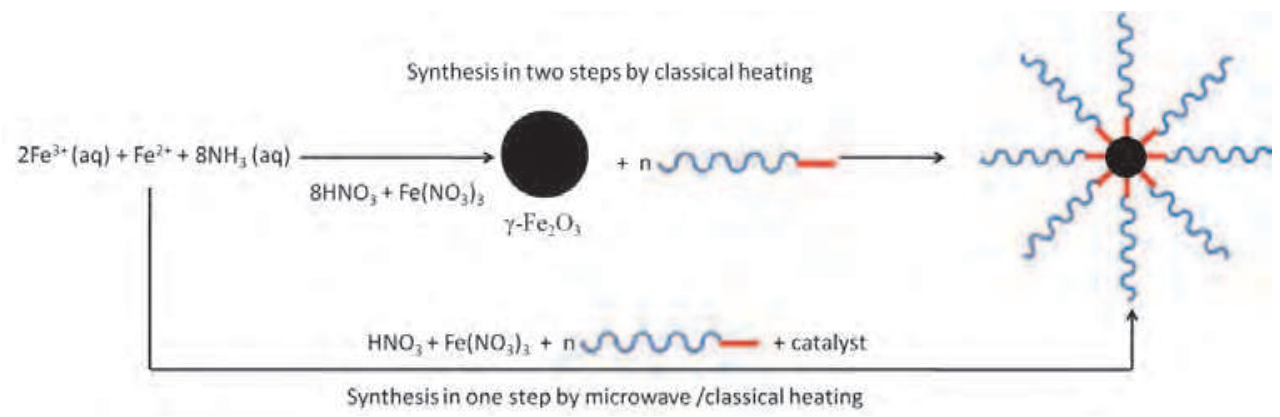

Fig. 10. Representation of preparations of magnetic nanohybrids in one and two steps by classical and microwave synthesis 
A comparison will be made between this microwave treatment with those prepared using classical heating mode (Figure 10) according to several criteria: particle size and crystallinity, reaction time and grafted amount of polymer on the nanoparticles.

\subsection{Experimental part}

\section{Synthesis of silanated mPEG (mPEG-Si)}

The trialkoxysilylated mPEG (mPEG-Si) was prepared by direct coupling of mPEG with IPTS through a urethane bond. IPTS was chosen as coupling agent to allow the grafting of mPEG chains at the surface of maghemite nanoparticles.

$40 \mathrm{~mL}$ of anhydrous THF is added to $16 \mathrm{~g}$ of dried mPEG under nitrogen. Then, $5.5 \mathrm{~mL}$ $(0.022 \mathrm{~mol})$ of IPTS and $0.56 \mathrm{ml}\left(0.9 .10^{-3} \mathrm{~mol}\right)$ of DBTL is added to the mPEG solution. The mixture is stirred continuously for $48 \mathrm{~h}$ under nitrogen. After the reaction, the silanated $\mathrm{mPEG}$ is precipitated into hexane $(400 \mathrm{~mL})$ and dried in vacuum at room temperature for $24 \mathrm{~h}$ (yield $=71 \%$ ).

According to the work published by Jo \& Park (2000), the $300 \mathrm{MHz}$ spectrum shows six sets of peaks:

${ }^{1} \mathrm{H}-\mathrm{NMR}\left(\mathrm{CDCl}_{3}, 300 \mathrm{MHz}\right): \delta=0.55\left(\mathrm{t}, 2 \mathrm{H}, J=8.3 \mathrm{~Hz},-\mathrm{CH}_{2} \mathrm{Si}\right), 1.16(\mathrm{t}, 9 \mathrm{H}, J=6.9 \mathrm{~Hz}$, $\left.-\mathrm{OCH}_{2} \mathrm{CH}_{3}\right), 1.49-1.59\left(\mathrm{~m}, 2 \mathrm{H},-\mathrm{CH}_{2} \mathrm{CH}_{2} \mathrm{CH}_{2} \mathrm{Si}\right), 3.31-3.82\left(\mathrm{~m}, 4 \mathrm{nH},-\left(\mathrm{CH}_{2} \mathrm{CH}_{2} \mathrm{O}\right){ }_{\mathrm{n}}^{-}\right), 4.14(\mathrm{t}, 2 \mathrm{H}$, $\left.J=4.7 \mathrm{~Hz},-\mathrm{CH}_{2} \mathrm{OC}(\mathrm{O}) \mathrm{NH}-\right), 4.94$ (s-large, $\left.1 \mathrm{H},-\mathrm{OC}(\mathrm{O}) \mathrm{NH}-\right)$. These results show that the functionalization step is complete at the end of the reaction with IPTS which is used in excess.

mPEG grafting onto maghemite nanoparticles

In the following procedures (Figure 10), the grafting of the maghemite nanoparticles is performed in water with a typical $w / w\left(\mathrm{Si}-\mathrm{mPEG} / \mathrm{\gamma}-\mathrm{Fe}_{2} \mathrm{O}_{3}\right)$ ratio of 10 . DBTL is added as a catalyst. After the reactions, the excess of Si-mPEG was removed by 10 centrifugationdispersion cycles in distilled water.

\section{Two-step grafting procedure by classical heating (Sample 1)}

The maghemite nanoparticles are synthesized in advance according to the procedure developed by Massart (1981). Briefly, $0.0019 \mathrm{~mol}$ of $\mathrm{FeCl}_{2}$ and $0.0038 \mathrm{~mol}$ of $\mathrm{FeCl}_{3}$ are mixed at $80{ }^{\circ} \mathrm{C}$ with $100 \mathrm{~mL}$ of distilled water. 10 minutes of agitation is carried out after adding $4.5 \mathrm{~mL}$ of $28 \%$ ammonia to the reaction mixture and magnetite black particles precipitate. Magnetite particles are oxidized with $7.5 \mathrm{~mL}$ of $\mathrm{HNO}_{3} 2 \mathrm{M}$ for $10 \mathrm{~min}$ and then with $7.5 \mathrm{~mL}$ of $\mathrm{Fe}\left(\mathrm{NO}_{3}\right)_{3} 0.33 \mathrm{M}$ solution at $80^{\circ} \mathrm{C}$ for $30 \mathrm{~min}$. $1 \mathrm{~mL}$ of freshly prepared ferrofluid reacts with $0.10 \mathrm{~g}$ of Si-mPEG at $80^{\circ} \mathrm{C}$ for one hour.

\section{One-step grafting procedure by classical heating (Sample 2)}

$0.00228 \mathrm{~mol}$ of $\mathrm{FeCl}_{2}, 0.00038 \mathrm{~mol}$ of $\mathrm{FeCl}_{3}$ and $0.00013 \mathrm{~mol}$ of Si-mPEG are dissolved at 80 ${ }^{\circ} \mathrm{C}$ in distilled water. 10 minutes of agitation is carried out after adding $0.45 \mathrm{~mL}$ of $28 \%$ ammonia to the reaction mixture and magnetite black particles precipitate. Nanoparticles are oxidized with $0.75 \mathrm{~mL}$ of $\mathrm{HNO}_{3} 2 \mathrm{M}$ for $10 \mathrm{~min}$ and then with $0.75 \mathrm{~mL}$ of $\mathrm{Fe}\left(\mathrm{NO}_{3}\right)_{3}$ $0.33 \mathrm{M}$ solution at $80^{\circ} \mathrm{C}$ for $30 \mathrm{~min}$.

\section{One-step grafting procedure by microwave heating (Sample 3)}

For this one-step synthesis, we didn't choose the laboratory microwave autoclave reactor for 3 reasons: (i) There is a possibility that the polymer clogs the system during the reaction; (b) the PEG does not support the operating temperature close to $180{ }^{\circ} \mathrm{C}$ in the laboratory 
microwave autoclave reactor and (c) the grafting in alcoholic medium is not proved. Thus the functionalization is performed by the microwave $(2.45 \mathrm{GHz})$ refluxing device.

The power used was $400 \mathrm{~W}$, higher microwave power might cause the difficult control of reaction system. $0.00228 \mathrm{~mol}$ of $\mathrm{FeCl}_{2}, 0.00038 \mathrm{~mol}$ of $\mathrm{FeCl}_{3}$ and $0.00013 \mathrm{~mol}$ of Si-mPEG are dissolved in water, then the reaction mixture is submitted to a microwave irradiation power of $400 \mathrm{~W}$ for $10 \mathrm{~min}$ after adding $0.45 \mathrm{~mL}$ of $28 \%$ ammonia and magnetite black particles precipitate. They are oxidized with $0.75 \mathrm{~mL}$ of $\mathrm{HNO}_{3} 2 \mathrm{M}$ and $0.75 \mathrm{~mL}$ of $\mathrm{Fe}\left(\mathrm{NO}_{3}\right)_{3} 0.33 \mathrm{M}$ solution under microwave irradiation for $10 \mathrm{~min}$ additional treatment.

The experimental conditions of these syntheses are summarized in Table 3 . The results show that maghemite nanoparticles can be synthesized by the microwave heating method in an attractive shorter time.

\begin{tabular}{|c|c|c|c|}
\hline Sample & Grafting protocol & Heating mode & Total reaction time (min) \\
\hline 1 & 2 steps & Classical & 110 \\
\hline 2 & 1 step & Classical & 50 \\
\hline 3 & 1 step & Microwave & 20 \\
\hline
\end{tabular}

Table 3. Reaction conditions of different nanohybrids synthesis

\subsection{Characterization of the grafted nanoparticles}

\section{Structural characterization}

In the case of one step grafting procedure, the grafting step occurs at the same time as the formation of the nanoparticles. The diffractogrammes imply that the nanoparticles have a cubic crystal structure (Figure 11).

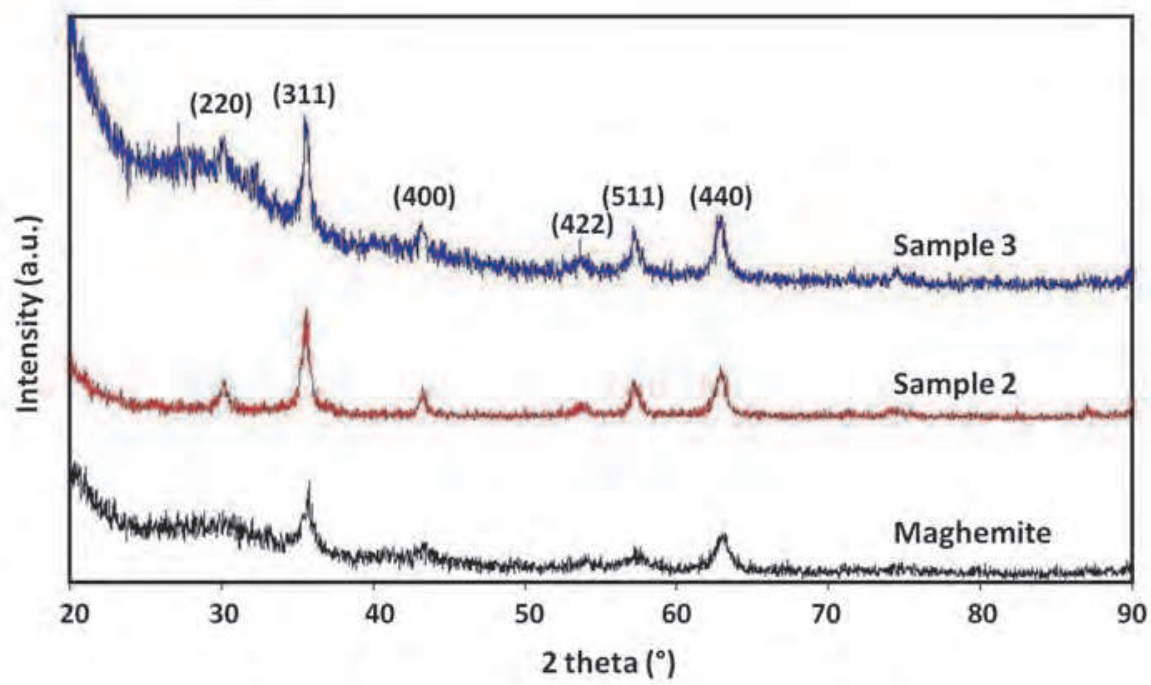

Fig. 11. Diffractograms of ungrafted and grafted maghemite nanoparticles 
Raman spectra allow us to confirm that these samples contain pure maghemite nanoparticles, by the presence of characteristic bands of maghemite phase around 350, 500 and $700 \mathrm{~cm}^{-1}$ (Figure 12). Nakashima et al. (2001) showed that the relative intensities of the bands are related to the crystallinity of the particles. The intensity of the bands of particles grafted by microwave reflux heating is stronger than those of particles grafted by conventional heating, which means that the microwave reflux heating tends to improve the crystallinity of the particles. The microwave system reflux can induce a very rapid heating rate throughout the system and lead to the instantaneous nucleation of monodisperse particles.

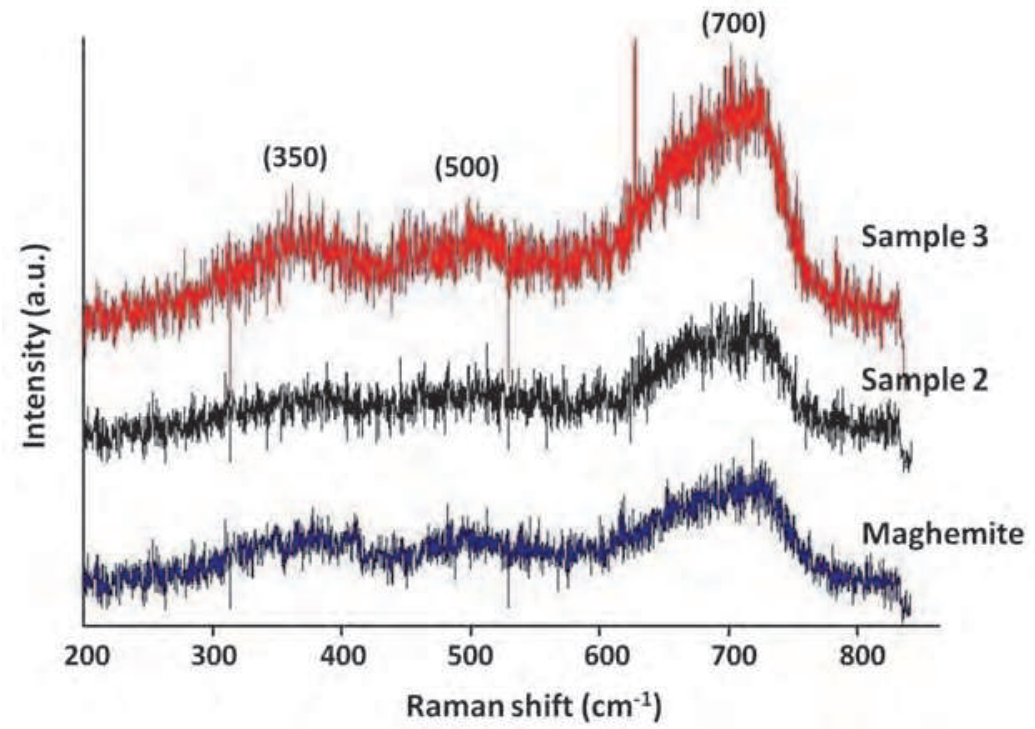

Fig. 12. Raman spectra of ungrafted and grafted maghemite nanoparticles

\section{Particle morphology and size}

The particle morphology is studied initially by Transmission Electron Microscopy (TEM). Nanosized almost spherical nanoparticles are observed (Figure 13). Table 4 reveals a good agreement with the average particle sizes determined by XRD profile analysis. The presence of the macromolecular chain is not visible on the images of grafted maghemite but the pictures reveal that the nanoparticles can be isolated.

\begin{tabular}{|c|c|c|}
\hline Sample & $d_{\text {DRX }}(\mathrm{nm})$ & $d_{\text {MET }}(\mathrm{nm})$ \\
\hline Maghemite & $14 \pm 2$ & $12 \pm 1$ \\
\hline 1 & - & $12 \pm 1$ \\
\hline 2 & $20 \pm 3$ & $20 \pm 1$ \\
\hline 3 & $18 \pm 3$ & $21 \pm 1$ \\
\hline
\end{tabular}

Table 4. Particle sizes determined by XRD and TEM 


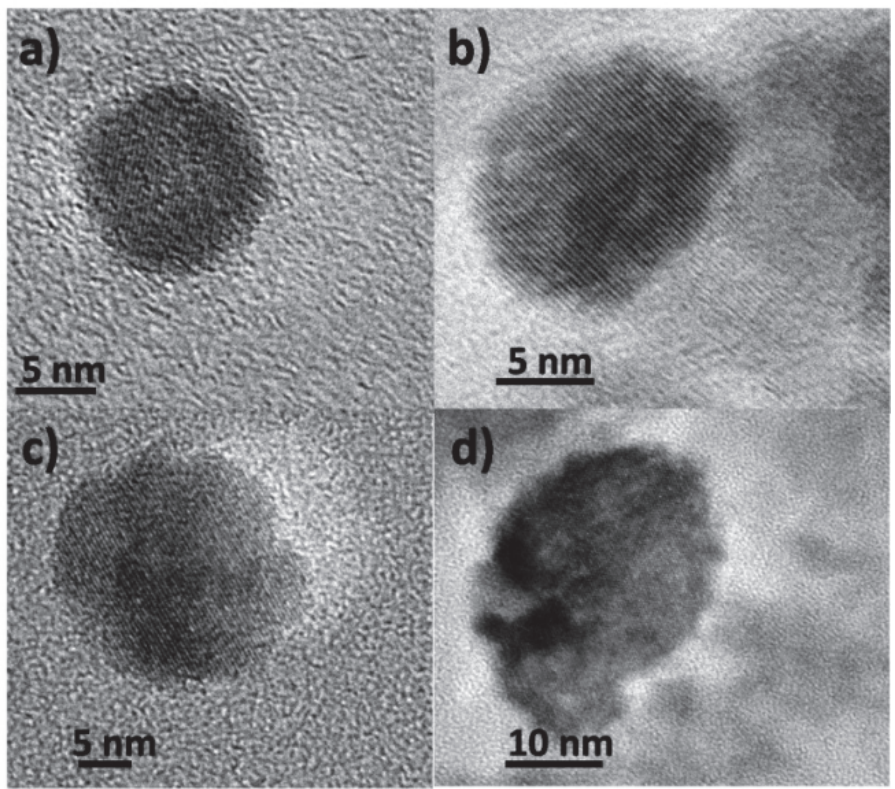

Fig. 13. TEM images of ungrafted (a) and grafted maghemite nanoparticles: sample 1 (b), sample 2 (c) and sample $3(\mathrm{~d})$

\section{Surface properties}

Zeta potential of ungrafted maghemite is $42.3 \mathrm{mV}$ (Table 5) which signifies that the solution is stable. The protonated hydroxyl groups present on their surface ensured efficient electrostatic stabilization of the iron oxide particles. The decrease of surface charge of the grafted samples showed successful PEG grafting. To explain this phenomenon, two reasons are suggested: neutralization of the positive charge of nanoparticles by a covalent bond with mPEG-Si or screening effect of the polymer covering the surface which hides the positive charge (Lu et al., 2007).

\begin{tabular}{|c|c|}
\hline Sample & Zeta Potential $(\mathrm{mV})$ \\
\hline Maghemite & $+42.3 \pm 2,1$ \\
\hline 1 & $-0.1 \pm 0,1$ \\
\hline 2 & $+0.2 \pm 0,1$ \\
\hline 3 & $+0.1 \pm 0,1$ \\
\hline
\end{tabular}

Table 5. Zeta potential of ungrafted and grafted maghemite nanoparticles

\section{Chemical bonds in the nanohybrids}

The comparison of FTIR spectra of the ungrafted and grafted nanoparticles, in the $400-2000$ $\mathrm{cm}-1$ range, is shown in Figure 14. The peaks at 631 and $567 \mathrm{~cm}^{-1}$ in the spectrum of ungrafted particles are assigned to the $\mathrm{Fe}-\mathrm{O}$ bond vibration of maghemite particles ( $\mathrm{Li}$ et al., 2004). The peak at $1384 \mathrm{~cm}^{-1}$ is attributed to the $v(\mathrm{~N}-\mathrm{O})$ deformation from the surface nitrates (Mornet et al., 2005). 
The spectrum of Si-mPEG is presented for the reference. The peak at $1715 \mathrm{~cm}^{-1}$ is attributed to the vibration of the urethane carbonyle bond $v(\mathrm{C}=\mathrm{O})$ (Kim et al., 2005). The presence of absorption peak at $1531 \mathrm{~cm}^{-1}$ reveals the presence of urethane bond $\delta(\mathrm{NH})$ (Schoonover et al., 2007). The peaks at 1466, 1348 and $1279 \mathrm{~cm}^{-1}$ are attributed to the vibration of $-\mathrm{CH}_{2}$ (Flesch et al., 2005a). The signal at $1240 \mathrm{~cm}^{-1}$ is attributed to the vibration of $v(\mathrm{C}-\mathrm{O})$ (Zhang et al., 2008). The band around $1105 \mathrm{~cm}^{-1}$ is due to the $v(\mathrm{Si}-\mathrm{O})$ vibration (Ma et al., 2003). The bands at 961 and $839 \mathrm{~cm}^{-1}$ correspond to the ethoxy groups $-\mathrm{OC}_{2} \mathrm{H}_{5}$ (Steitz et al., 2007). The absorption band at $943 \mathrm{~cm}^{-1}$ belongs to -CH out-of-plane bending vibration of PEG (Zhang et al., 2002).

The characteristic peaks of mPEG-Si appear on the spectra of grafted maghemite, besides the Fe-O signals of maghemite: $v(\mathrm{C}=\mathrm{O})$ at $1695 \mathrm{~cm}^{-1}, \delta(\mathrm{NH})$ at $1539 \mathrm{~cm}^{-1}, \delta\left(\mathrm{CH}_{2}\right)$ at $1452 \mathrm{~cm}^{-1}$, $\mathrm{T}\left(\mathrm{CH}_{2}\right)$ at $1348 \mathrm{~cm}^{-1}, \omega\left(\mathrm{CH}_{2}\right)$ at $1285 \mathrm{~cm}^{-1}, v(\mathrm{C}-\mathrm{O})$ at $1246 \mathrm{~cm}^{-1}$ and $\omega(-\mathrm{CH})$ at $943 \mathrm{~cm}^{-1}$. All these vibrations confirm that Si-mPEG is well grafted at the surface of maghemite particles. The absorption band at $1624 \mathrm{~cm}^{-1}$ refers to the vibration of remaining $\mathrm{H}_{2} \mathrm{O}$ on the sample (Mena Duran et al., 2007). The Si-mPEG is adsorbed on the maghemite surface by a Fe-O-Si bond. However, in the literature, this band is situated around $584 \mathrm{~cm}^{-1}$ and therefore overlaps with the Fe-O vibration of maghemite (Yamaura et al., 2004). The vibration of the carbonyle bond is shifted from 1715 to $1695 \mathrm{~cm}^{-1}$ after grafting, since this bond is weakened by hydrogen bonds that are formed between carbonyl and surface hydroxy groups (Posthumus et al., 2004). The disappearance of the characteristic peaks for the ethoxy groups at 961 and $839 \mathrm{~cm}^{-1}$ shown in the spectrum of silanated m-PEG, indicates that hydrolysis

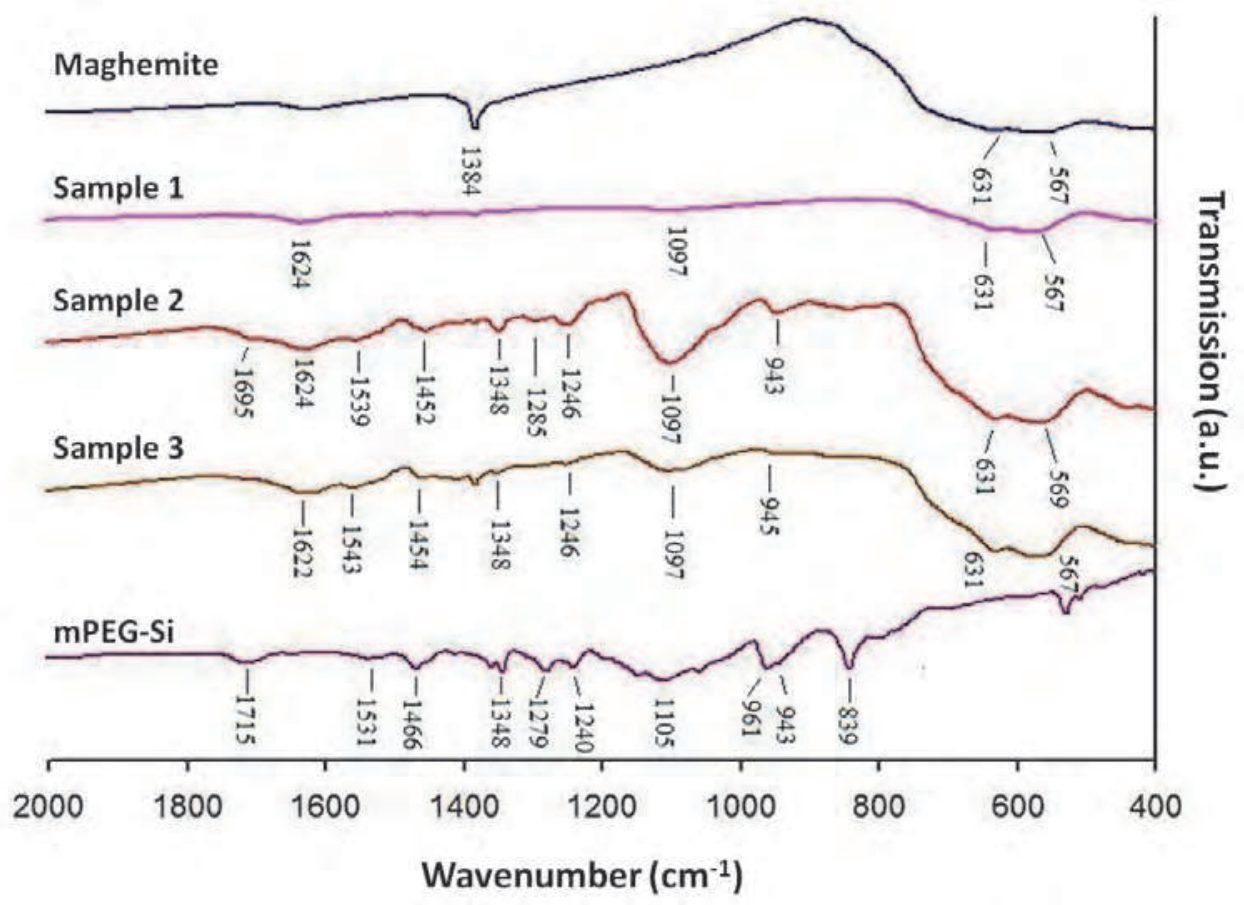

Fig. 14. FTIR spectra of ungrafted and grafted maghemite nanoparticles and spectrum of mPEG-Si shown for reference 
took place. The large band around $1097 \mathrm{~cm}^{-1}$ is due to the $v(\mathrm{Si}-\mathrm{O}-\mathrm{Si})$ vibration which shows that the triethoxysilane groups have self condensed to form a polysiloxane film on the maghemite surface. The organosilane is hydrolyzed in aqueous solution, alkoxide groups $\mathrm{OC}_{2} \mathrm{H}_{5}$ are replaced by hydroxyl groups $-\mathrm{OH}$ to form reactive silanol groups which condense with other silanol groups to produce siloxane bonds Si-O-Si. The presence of the group Si-O-Si confirmed that the last mechanism took place in our case.

\section{Grafted amounts of polymers}

The grafted amount of mPEG-Si determined by thermogravimetric analysis (TGA) reveals the effectiveness of mPEG-Si grafting whatever the grafting methods used (Table 6). It has been calculated from the difference in losses between the grafted maghemite and the ungrafted maghemite in the temperature range between 30 and $850{ }^{\circ} \mathrm{C}$.

\begin{tabular}{|c|c|c|c|c|}
\hline Sample & $\begin{array}{c}\text { Heating } \\
\text { energy }\end{array}$ & $\begin{array}{c}\text { Total reaction time } \\
(\mathrm{min})\end{array}$ & $\begin{array}{c}\text { Weight loss } \\
(\%)\end{array}$ & $\begin{array}{c}\text { Difference in weight loss } \\
(\%)\end{array}$ \\
\hline Maghemite & Classical & 50 & 6 & 0 \\
\hline 1 & Classical & 110 & 16 & 10 \\
\hline 2 & Classical & 50 & 21 & 15 \\
\hline 3 & Microwave & 20 & 18 & 12 \\
\hline
\end{tabular}

Table 6. Grafted amount of samples 1, 2 and 3

Weight losses of $15 \%$ and $12 \%$ of grafted mPEG-Si at the nanoparticles surface were determined for the two samples prepared by the one step procedure. These values are slightly superior to the one obtained by the two steps procedure $(10 \%)$. However, the one step procedures take less time to reach this grafted amount. Especially, the sample 3 prepared by the microwave refluxing allows to reduce $82 \%$ of the reaction time. Compared to the classical two steps method, microwave heating provides the best grafting rate of mPEG onto nanoparticles. Ge et al. (2006) has shown the same tendency in his work. These results show that the microwave heating can increase the grafting rate over the conventional method.

\subsection{Conclusion}

In this part, we studied the preparation of magnetic nanohybrids by microwave heating, compared with the classical system. One two-step and two one-step procedures in terms of PEG grafting onto maghemite nanoparticles in aqueous medium were compared. In all cases, the formation of pure polycrystalline maghemite nanoparticles was proved by XRD and Raman analysis, the PEG grafting was evidenced by FTIR spectroscopy and by means of zeta potential measurements, and the grafted amount was determined by TGA. The main difference between microwave heating and conventional heating is a consequent time saving. It is obvious that one-step microwave heating procedure gives the same amount of PEG grafting by using less reaction time (82\% shorter) than the other two methods. Moreover, Raman studies reveal that microwave treatment tends to result in better crystallized particles. Microwave heating provides a simple and convenient way for the PEG grafting that could potentially be useful in the field of magnetic nanohybrids. 


\section{Conclusion}

The magnetic nanohybrids (magnetic core/biocompatible polymeric corona) are increasingly used in medical imaging applications, for drug delivery, for hyperthermia treatment...

While conventional methods for the synthesis of nanohybrids have the disadvantages of changing solvent and to be long, we have proposed simplistic approaches. The use of polymer functionalized with an anchor allows to achieve grafting directly in aqueous medium containing magnetic oxide nanoparticles. Another improvement is to grow the magnetic nanoparticles in the presence of polymer chains linked with an anchor: this procedure guarantees the non-agglomeration of nanoparticles and the grafting of individual particles. Finally we take advantage of microwave heating (core heating, high heating power, high speed of temperature rise, uniform heating ...) for the synthesis of nanohybrids in aqueous medium. The microwave was used to obtain magnetic particles of pure $\gamma-\mathrm{Fe}_{2} \mathrm{O}_{3}$, with a good crystallinity, of monodisperse sizes $(21 \mathrm{~nm})$ and a grafting amount of PEG identical to that obtained by the conventional methods but with a synthesis time considerably shorter, at least 5 times faster.

This approach can be applied to other hybrid systems and for many other applications: in plant biology, in cosmetics, in cements, in paints, in formulation...

\section{References}

Baghi, M., Mack, M. G., Hambek, M., Rieger, J., Vogl, T., Gstoettner, W. \& Knecht, R. (2005). The efficacy of MRI with ultrasmall superparamagnetic iron oxide particles (USPIO) in head and neck cancers, Anticancer Research, Vol. 25, No. 5, pp. 3665-3670

Barruet, J. (2007). Polymères réactifs à base d'isocyanates bloqués: développement de méthodologies de synthèse pour la bioconjugaison, PhD thesis, University of Paris 12

Bellon, K. (2000). Elaboration de sols et de poudres nanométriques par hydrolyse force microonde. Applications aux oxydes de fer (III) et de zirconium (IV), PhD thesis, University of Burgundy

Bellon, K., Chaumont, D. \& Stuerga, D. (2001). Flash synthesis of zirconia nanoparticles by microwave forced hydrolysis, Journal of Materials Research, Vol. 16, pp. 2619-2622

Berry, C. C., Wells, S., Charles, S. \& Curtis, A. S. G. (2003). Dextran and albumin derivatised iron oxide nanoparticles: influence on fibroblasts in vitro, Biomaterials, Vol. 24, pp. 45514557

Bonnans-Plaissance, C., Levesque, G. \& Toulin, V. (2001). Functionalization of PS and PMMA by a chain transfer agent and study of their degradation, Reactive \& Functional Polymers, Vol. 47, pp. 77-85

Bousquet-Berthelin, C., Chaumont, D. \& Stuerga, D. (2008). Flash microwave synthesis of trevorite nanoparticles, Journal of Solid State Chemistry, Vol. 181, pp. 616-622

Brachais, C.-H., Hu, L., Hach, D., Chaumont, D., Percheron, A. \& Couvercelle, J.-P. (2010). Aqueous chemical grafting of modified-PEG onto maghemite nanoparticles: Influence of grafting conditions, e-polymers

Brigger, I., Dubernet, C. \& Couvreur, P. (2002). Nanoparticles in cancer therapy and diagnosis, Advanced Drug Delivery Reviews, Vol. 54, pp. 631-651

Brosse, C., Hamdaoui, A. E., Soutif, J. C. \& Brosse, J. C. (1995). Synthèse de polyuréthanes utilisables pour des techniques de microencapsulation -I. Modification chimique d'alcool 
polyvinylique par des isocyanates d'alkyle, European Polymer Journal, Vol. 31, pp. 425429

Buurma, N. J., Blandamer, M. J. \& Engberts, B. F. N. (2003). General-base catalyzed hydrolysis and nucleophilic substitution of activated amides in aqueous solutions, Journal of Physical Organic Chemistry, Vol. 16, pp. 438-449

Caillot, T., Aymes, D., Stuerga, D., Viart, N. \& Pourroy, G. (2002). Microwave flash synthesis of iron and magnetite particles by disproportionation of ferrous alcoholic solutions, Journal of Materials Science, Vol. 37, pp. 1-6

Caillot, T., Pourroy, G. \& Stuerga, D. (2004). Microwave hydrothermal flash synthesis of nanocomposites Fe-Co alloy/cobalt ferrite, Journal of Solid State Chemistry, Vol. 177, pp. 3843-3848

Changez, M., Burugapalli, K., Koul, V. \& Choudhary, V. (2003). The effect of composition of poly(acrylic acid)-gelatin hydrogel on gentamicin sulphate release: in vitro, Biomaterials, Vol. 24, pp. 527-536

Chen, M., Zamora, P. O., Som, P., Pena, L. A. \& Osaki, S. (2003) Cell attachment and biocompatibility of polytetra uoroethylene (PTFE) treated with glow-discharge plasma of mixed ammonia and oxygen, Journal of Biomaterials Science, Polymer Edition, Vol. 14, pp. 917-935

Choi, J. Y. \& Kim, D. K. (1999). Preparation of monodisperse ans spherical powders by heating of alcohol-aqueous salt solutions, Journal of Sol-Gel Science and Technology, Vol. 15, pp. 231-241

Cirera, A., Vila, A. \& Dieguez, A. (2000). Microwave processing for the low cost, mass production of undoped and in situ catalytic doped nanosized $\mathrm{SnO}_{2}$ gas sensor powders, Sensors and Actuators, Vol. 64, pp. 65-69

Combemale, L., Caboche, G, Stuerga, D \& Chaumont, D. (2005). Microwave synthesis of yttria stabilized zirconia, Materials Research Bulletin, Vol. 40, pp. 529-536

Daichuan, D., Pinjie, H. \& Shushan, D. (1995). Preparation of uniform $\beta-F e O(O H)$ colloidal particles by hydrolysis of ferric salts under microwave irradiation, Materials Research Bulletin, Vol. 30, pp. 537-541

Dallas, P., Moutis, N., Devlin, E., Niarchos, D. \& Petridis, D. (2006). Characterization, electrical and magnetic properties of polyaniline/maghemite nanocomposites, Nanotechnology, Vol. 17, pp. 5019-5026

Davis, S. S. (1997). Biomedical applications of nanotechnology-implication for drug targeting and gene therapy, TIBTECH, Vol. 15, pp. 217-224.

Delair, T., Elaissari, A., Perrin, A. \& Mandrand, B. (2003). Les polymères de synthèse, supports du diagnostic médical, pp. 79-84

Désévaux, C. (2002). Développement d'un implant solide biodegradable à base d'amidon réticulé à teneur élevée en amylose pour la libération contrôlée d'un principe actif, $\mathrm{PhD}$ thesis, University of Montréal

Drakakis, E. M., Toumazou, C. \& Cass, A. E. G. (2008). Biocompatible ion selective electrode for monitoring metabolic activity during the growth and cultivation of human cells, Biosensors and Bioelectronics, Vol. 24, pp. 435-441

D'Souza, A. J. M., Schowen, R. L. \& Topp, E. M. (2004). Polyvinylpyrrolidone-drug conjugate: synthesis and release mechanism, Journal of Controlled Release, Vol. 94, pp. 91-100

Fan, Q. L., Neoh, K. G., Kang, E. T., Shuter, B. \& Wang, S. C. (2007). Solvent-free atom transfer radical polymerization for the preparation of poly(poly(ethyleneglycol) monomethacrylate)- 
grafted $\mathrm{Fe}_{3} \mathrm{O}_{4}$ nanoparticles: synthesis, characterization and cellular uptake, Biomaterials, Vol. 28, pp. 5426-5436

Flesch, C., Delaite, C., Dumas, P., Bourgeat-Lami, E. \& Duguet, E. (2004). Grafting of poly(Ecaprolactone) onto maghemite nanoparticles, Journal of Polymer Science: Part A: Polymer Chemistry, Vol. 42, pp. 6011-6020

Flesch, C., Jourbert, M., Bourgeat-Lami, E., Mornet, S., Duguet, E., Delaite, C. \& Dumas, P. (2005a). Organosilane-modified maghemite nanoparticles and their use as co-initiator in the ring-opening polymerization of $\varepsilon$-caprolactone, Colloids and Surfaces A: Physicochemical and Engineering Aspects, Vol. 262, pp. 150-157

Flesch, C., Bourgeat-Lami, E., Mornet, S., Duguet, E., Delaite, C. \& Dumas, P. (2005b). Synthesis of colloidal superparamagnetic nanocomposites by grafting poly(E-caprolactone) from the surface of organosilane-modified maghemite nanoparticles, Journal of Polymer Science: Part A: Polymer Chemistry, Vol. 43, pp. 3221-3231

Flesch, C., Unterfinger, Y., Bourgeat-Lami, E., Duguet, E., Delaite, C. \& Dumas, P. (2005c). Poly(ethylene glycol) surface coated magnetic particles, Macromolecular Rapid Communications, Vol. 26, pp. 1494-1498

Gaur, U., Sahoo, S. K., De, T. K., Ghosh, P. C., Maitra, A. \& Ghosh, P. (2000). Biodistribution of fluoresceinated dextran using novel nanoparticles evading reticuloendothelial system, International Journal of Pharmaceutics, Vol. 202, pp. 1-10

Ge, H. C., Pang, W. \& Luo, D. (2006). Graft copolymerization of chitosan with acrylic acid under microwave irradiation and its water absorbency, Carbohydrate Polymers, Vol. 66, pp. 372-378

Grignon-Dubois, M., Dunoguès, J. \& Calas, R. (1980). Influence de la taille du cycle sur la substitution électrophile des cycloalkyltriméthylsilanes. Synthèse de cycloalkyldiméthylfluorosilanes, Canadian Journal of Chemistry, Vol. 58, pp. 291-295

Grisaru, H., Palchik, O., Gedanken, A., Palchik, V., Slifkin, M. A. \& Weiss, A. M. (2003). Microwave-assisted polyol synthesis of $\mathrm{CuInTe}_{2}$ and $\mathrm{CuInSe}_{2}$ nanoparticles, Inorganic Chemistry, Vol. 42, pp. 7148-7155

Gupta, A. K. \& Curtis, A. S. G. (2004). Surface modified superparamagnetic nanoparticles for drug delivery: interaction studies with human fibroblasts in culture, Journal of Materials Science: Materials in Medicine, Vol. 15, pp. 493-496

Harpeness, R. \& Gedanken, A. (2005). The microwave-assisted polyol synthesis of nanosized hard magnetic material, FePt, Journal of Materials Chemistry, Vol. 15, pp. 698-702

Houghton, R. P. \& Mulvaney, A. W. (1996). Mechanism of tin(IV)-catalyzed urethane formation, Journal of Organometallic Chemistry, Vol. 518, pp. 21-27

$\mathrm{Hu}$, L., Hach, D., Chaumont, D., Brachais, C.-H. \& Couvercelle, J.-P. (2008). One step grafting of monomethoxy poly(ethylene glycol) during synthesis of maghemite nanoparticles in aqueous medium, Colloids and Surfaces A: physicochemical and engineering, Vol. 330, pp. 1-7

Jo, S. B. \& Park, K. N. (2000). Surface modification using silanated poly(ethylene glycol)s, Biomaterials, Vol. 21, pp. 605-616

Kelnar, I. \& Schätz, M. (1993). Silane cross-linking of PVC. I. Grafting of mercaptoalkylalkoxysilanes onto PVC: properties of the grafted and cross-linked product, Journal of Applied Polymer Science, Vol. 48, pp. 657-668

Khor, E. \& Lim, L. Y. (2003). Implantable applications of chitin and chitosan, Biomaterials, Vol. 24, pp. 2339-2349 
Kim, H., Lim, C. \& Hong, S. I. (2005). Gas permeation properties of organic-inorganic hybrid membranes prepared from hydroxyl-terminated polyester and 3isocyanatopropyltriethoxysilane, Journal of Sol-Gel Science and Technology, Vol. 36, pp. 213-221

Komarneni, S., Li, D. \& Newalkar, B. (2002). Microwave-polyol process for Pt and Ag nanoparticles, Langmuir, Vol. 18, pp. 5959-5962

Kubaska, S., Sahani, D. V., Saini, S., Hahn, P. F. \& Halpern, E. (2001). Dual contrast enhanced magnetic resonance imaging of the liver with superparamagnetic iron oxide followed by gadolinium for lesion detection and characterization, Clinical Radiology, Vol. 56, pp. 410-415

Kulikov, F. A., Vanetsev, A. S., Muav'eva, G. P., II'inskii, A. L., Oleinikov, N. N. Tret'yakov, Y. D. (2003). Microwave synthesis of $\gamma-\mathrm{Fe}_{2} \mathrm{O}_{3}$, Inorganic Materials, Vol. 39, pp. 1074-1075

Lee, H. Y., Lim, N. H., Seo, J. A., Yuk, S. H., Kwak, B. K., Khang, G., Lee, H. B. \& Cho, S. H. (2006). Preparation and magnetic resonance imaging effect of polyvinylpyrrolidone-coated iron oxide nanoparticles, Journal of Biomedical Materials Research Part B: Applied Biomaterials, Vol. 79, pp. 142-150

Li, J., Zeng, H., Sun, S., Liu, P. \& Wang, L. (2004). Analyzing the structure of $\mathrm{CoFe}-\mathrm{Fe}_{3} \mathrm{O}_{4}$ coreshell nanoparticles by electron imaging and diffraction, Journal of Physical Chemistry B, Vol. 108, pp. 14005-14008

Lu, A. H., Salabas, E. L. \& Schüth, F. (2007). Magnetic nanoparticles: synthesis, protection, functionalization, and application, Angewandte Chemie International Edition, Vol. 46, pp. 1222-1244

Lu, W. G., Yang, D. Q., Sun, Y., Guo, Y., Xie, S. P. \& Li, H. L. (1999). Preparation and structural characterization of nanostructured iron oxide thin films, Applied Surface Science, Vol. 147, pp. 39-43

Ma, M., Zhang, Y., Yu, W., Shen, H. Y., Zhang, H. Q. \& Gu, N. (2003). Preparation and characterization of magnetite nanoparticles coated by amino silane, Colloids and Surfaces A : physicochemical and engineering aspects, Vol. 212, pp. 219-226

Maillard, S., Gauduchon, J., Marsaud, V., Gouilleux, F., Connault, E., Opolon, P., Fattal, E., Sola, B. \& Renoir, J. M. (2006). Improved antitumoral properties of pure antiestrogen RU 58668-loaded liposomes in multiple myeloma, Journal of Steroid Biochemistry \& Molecular Biology, Vol. 100, pp. 67-78

Massart, R. (1981). Preparation of aqueous magnetic liquids in alkaline and acidic media, IEEE Transactions on magnetics, Vol. 17, pp. 1247-1248

Meerod, S., Tumcharem, G., Wichai, U. \& Rutnakornpituk, M. (2008). Magnetite nanoparticles stabilized with polymeric bilayer of poly(ethylene glycol) methyl ether-poly(E-caprolactone) copolymers, Polymer, Vol. 49, pp. 3950-3956

Mena-Duran, C. J., Sun Kou, M. R., Lopez, T., Azamar-Barrios, J. A., Aguilar, D. H., Dominguez, M. I., Odriozola, J. A. \& Quintana, P. (2007). Nitrate removal using natural clays modified by acid thermoactivation, Applied Surface Science, Vol. 253, pp. $5762-5766$

Michel, E. (2003a). Thermohydrolyse micro-onde: des nanoparticles aux films minces. Applications à $\mathrm{SnO}_{2}$ et $\mathrm{TiO}_{2}$ rutile et anatase, $\mathrm{PhD}$ thesis, University of Burgundy, France

Michel, E., Stuerga, D. \& Chaumont, D. (2001). Microwave flash synthesis of tin dioxide sols from tin chloride aqueous solutions, Journal of Material Science Letters, Vol. 20, pp. 15931595 
Michel, E., Chaumont, D. \& Stuerga, D. (2003b). $\mathrm{SnO}_{2}$ thin films prepared by dip-coating from microwave synthesized colloidal suspensions, Journal of Colloid and Interface Science, Vol. 257, pp. 258-262

Mornet, S., Portier, J. \& Duguet, E. (2005). A method for synthesis and functionalization of ultrasmall superparamagnetic covalent carriers based on maghemite and dextran, Journal of Magnetism and Magnetic Materials, Vol. 293, pp. 127-134

Mowat, P. (2007). IRM cellulaire de lymphocytes marques par des nanoparticules d'oxydes de fer: application au diagnostic en cancerologie, $\mathrm{PhD}$ thesis, University of Angers

Nakashima, S., Nakatake, Y., Ishida, Y., Talkahashi, T. \& Okumura, H. (2001). Detection of defects in SiC crystalline films by Raman scattering, Physica B, Vol. 308-310, pp. 684686

Narkis, M., Tzur, A. \& Vaxman, A. (1985). Some properties of silane-grafted moisture-crosslinked polyethylene, Polymer Engineering and Science, Vol. 25, pp. 857-862

Ninjbadgar, T., Yamamoto, S. \& Fukuda, T. (2004). Synthesis and magnetic properties of the $\gamma$ $\mathrm{Fe}_{2} \mathrm{O}_{3} /$ poly-(methyl methacrylate)-core/shell nanoparticles, Solid State Science, Vol. 6, pp. 879-885

Pinto-Gateau, N. (1995). Chauffage microonde et résonance dimensionnelle. Des concepts aux applications en géométrie cylindrique, PhD thesis, University of Burgundy, France

Plassat, V., Martina, M. S., Barratt, G., Marsaud, V., Ménager, C., Renoir, J. M. \& Lesieur, S. (2008). Liposomes superparamagnétiques PEG-yles pour l'IRM et la thérapie anticancéreuse: pharmacocinétique, biodistribution et étude in-vitro sur cellules MCF-7, Fourth meeting of the Conference of "Vectorisation de molécules actives et ciblage biologique" (Bordeaux, France)

Posthumus, W., Magusin, P. C. M. M., Brokken-Zijp, J. C. M., Tinnemans, A. H. A. \& Van der Linde, R. (2004). Surface modification of oxidic nanoparticles using 3methacryloxypropyltrimethoxysilane, Journal of Colloid and Interface Science, Vol. 269, pp. 109-116

Ramirez, L. P. \& Landfester, K. (2003). Magnetic polystyrene nanoparticles with a high magnetite content obtained by miniemulsion processes, Macromolecular Chemistry and Physics, Vol. 204, pp. 22-31

Rana, S., Gallo, A., Srivastava, R. S. \& Misra, R. D. K. (2007). On the suitability of nanocrystalline ferrites as a magnetic carrier for drug delivery: functionalization, conjugation and drug release kinetics, Acta Biomaterialia, Vol. 3, pp. 233-242

Reddy, K. R., Lee, K. P., Gopalan, A. I. \& Kang, H. D. (2007). Organosilane modified magnetite nanoparticles/poly(aniline-co-o/m-aminobenzenesulfonic acid) composites: synthesis and characterization, Reactive \& Functional Polymers, Vol. 67, pp. 943-954

Schoonover, J. R., Steckle Jr., W. P., Cox, J. D., Johnston, C. T., Wang, Y., Gillikin, A. M. \& Palmer, R. A. ((2007). Humidity-dependent dynamic infrared linear dichroism study of a poly(ester urethane), Spectrochimica Acta Part A, Vol. 67, pp. 208-213

Schultz, J. F., Bell, J. D., Goldstein, R. M., Kuhn, J. A. \& McCarty, T. M. (1999). Hepatic tumor imaging using iron oxide MRI: comparison with computed tomography, clinical impact, and cost analysis, Annals of Surgical Oncology, Vol. 6, No. 7, pp. 691-698

Shan, G. B., Xing, J. M., Luo, M. F., Liu, H. Z. \& Chen, J. Y. (2003) Immobilization of pseudomonas delafieldii with magnetic polyvinyl alcohol beads and its application in biodesulfurization, Biotechnology Letters, Vol. 25, pp. 1977-1981 
Sindhu, S., Jegadesan, S., Parthiban, A. \& Valiyaveettil, S. (2006). Synthesis and characterization of ferrite nanocomposite spheres from hydroxylated polymers, Journal of Magnetism and Magnetic Materials, Vol. 296, pp. 104-113

Sreeja, V. \& Joy, P. A. (2007). Microwave-hydrothermal synthesis of $\gamma-\mathrm{Fe}_{2} \mathrm{O}_{3}$ nanoparticles and their magnetic properties, Materials Research Bulletin, Vol. 42, pp. 1570-1576

Steitz, B., Hofmann, H. \& Petri-Fink, A. (2007). Production and biofunctionalization of magnetic nanobeads for magnetic separation of messenger RNA, Biophysical Reviews and Letters, Vol. 2, pp. 109-122

Stuerga, D. \& Gaillard, P. (1996). Microwave heating as a new way to induce localized enhancements of reaction rate, non-isothermal and heterogeneous kinetics, Tetrahedron, Vol. 52, pp. 5505-5510

Takafuji, M., Ide, S., Ihara, H. \& Xu, Z. (2004). Preparation of poly(1-vinylimidazole)-grafted magnetic nanoparticles and their application for removal of metal ions, Chemistry of Materials, Vol. 16, pp. 1977-1983

Thanh, S. P., Gaslain, F. \& Leblanc, M. (2000). Rapid synthesis of hybrid fluorides by microwave heating, Journal of Fluorine Chemistry, Vol. 101, pp. 161-163

Wada, S., Tazawa, K., Furuta, I. \& Nagae, H. (2003). Antitumor effect of new local hyperthermia using dextran magnetite complex in hamster tongue carcinoma, Oral Diseases, Vol. 9, pp. 218-223

Werne, T. V. \& Patten, T. E. (2001). Atom transfer radical polymerization from nanoparticles: a tool for the preparation of well-defined hybrid nanostructures and for understanding the chemistry of controlled/living radical polymerizations from surfaces, Journal of American Chemical Society, Vol. 123, pp. 7497-7505

Yamaura, M., Camilo, R. L., Sampaio, L. C., Macedo, M. A., Nakamura, M. \& Toma, H. E. (2004). Preparation and characterization of (3-aminopropyl) triethoxysilane-coated magnetite nanoparticles, Journal of Magnetism and Magnetic Materials, Vol. 279, pp. 210-217

Zhang, J., Rana, S., Srivastava, R. S. \& Misra, R. D. (2008). On the chemical synthesis and drug delivery response of folate receptor-activated, polyethylene glycol-functionalized magnetite nanoparticles, Acta Biomaterialia, Vol. 4, pp. 40-48

Zhang, Y., Kohler, N. \& Zhang, M. Q. (2002). Surface modification of superparamagnetic magnetite nanoparticles and their uptake, Biomaterials, Vol. 23, pp. 1553-1561

Zhou, L. L., Yuan, J. Y., Yuan, W. Z., Sui, X. F., Wu, S. Z., Li, Z. L. \& Shen, D. Z. (2009). Synthesis, characterization, and controllable drug release of $p H$-sensitive hybrid magnetic nanoparticles, Journal of Magnetism and Magnetic Materials, Vol. 321, pp. 2799-2804

Michel, E., Stuerga, D. \& Chaumont, D. (2001). Microwave flash synthesis of tin dioxide sols from tin chloride aqueous solutions, Journal of Material Science Letters, Vol. 20, pp. 15931595 


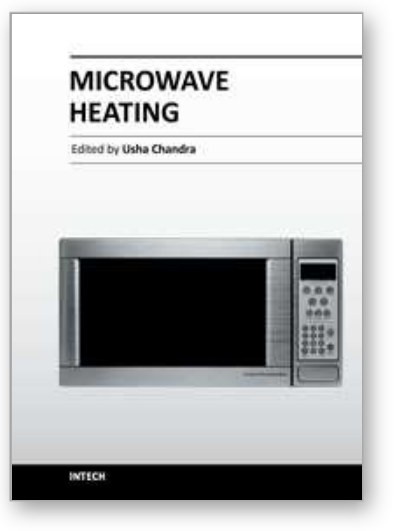

\author{
Microwave Heating \\ Edited by Dr. Usha Chandra
}

ISBN 978-953-307-573-0

Hard cover, 370 pages

Publisher InTech

Published online 27, July, 2011

Published in print edition July, 2011

The Microwave heating has not only revolutionized the food industry but also has extended its wings widely towards its multidimensional applications. Thus it has opened new vistas of potential research in science and technology. The book is compiled into Seventeen Chapters highlighting different aspects varying from epistemological discussion to applicability of conceptual constructs. The inclusion of discussion on the avenues in the field of Chemistry, Health \& Environment, Medical Sciences and Technology makes it an exquisite work for the aspirant Researchers. As the text book for the beginners, it is designed fundamentally to be a reference monograph to the experts providing a passage for future research. The plethora of literatures are available on Microwave Applications but they seldom direct their readers to concentrate on the key aspects behind the success in microwave applications in different fields. Here is the attempt to fill up the gap with this book.

\title{
How to reference
}

In order to correctly reference this scholarly work, feel free to copy and paste the following:

Ling Hu, Aurelien Percheron, Denis Chaumont and Claire-Helene Brachais (2011). Microwave synthesis of core-shell structured biocompatible magnetic nanohybrids in aqueous medium, Microwave Heating, Dr. Usha Chandra (Ed.), ISBN: 978-953-307-573-0, InTech, Available from:

http://www.intechopen.com/books/microwave-heating/microwave-synthesis-of-core-shell-structuredbiocompatible-magnetic-nanohybrids-in-aqueous-medium

\section{INTECH}

open science | open minds

\section{InTech Europe}

University Campus STeP Ri

Slavka Krautzeka 83/A

51000 Rijeka, Croatia

Phone: +385 (51) 770447

Fax: +385 (51) 686166

www.intechopen.com

\section{InTech China}

Unit 405, Office Block, Hotel Equatorial Shanghai

No.65, Yan An Road (West), Shanghai, 200040, China

中国上海市延安西路65号上海国际贵都大饭店办公楼 405 单元

Phone: +86-21-62489820

Fax: $+86-21-62489821$ 
(C) 2011 The Author(s). Licensee IntechOpen. This chapter is distributed under the terms of the Creative Commons Attribution-NonCommercialShareAlike-3.0 License, which permits use, distribution and reproduction for non-commercial purposes, provided the original is properly cited and derivative works building on this content are distributed under the same license. 